\title{
Impact of Lateral Boundary Errors on the Simulation of Clouds with a Nonhydrostatic Regional Climate Model
}

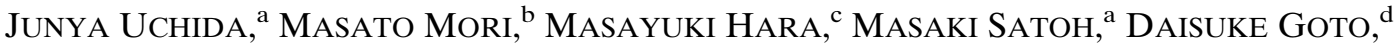 \\ TAKAHITO KATAOKA, ${ }^{a}$ KENTAROH SUZUKI, ${ }^{a}$ AND TERUYUKI NAKAJIMA ${ }^{\mathrm{e}}$ \\ ${ }^{a}$ Atmosphere and Ocean Research Institute, University of Tokyo, Chiba, Japan \\ ${ }^{\mathrm{b}}$ Research Center for Advanced Science and Technology, University of Tokyo, Tokyo, Japan \\ ${ }^{\mathrm{c}}$ Center for Environmental Science in Saitama, Saitama, Japan \\ ${ }^{\mathrm{d}}$ National Institute for Environmental Studies, Ibaraki, Japan \\ ${ }^{\mathrm{e}}$ Earth Observation Research Center, Japan Aerospace Exploration Agency (JAXA), Ibaraki, Japan
}

(Manuscript received 6 June 2017, in final form 4 October 2017)

\begin{abstract}
A nonhydrostatic, regional climate limited-area model (LAM) was used to analyze lateral boundary condition (LBC) errors and their influence on the uncertainties of regional models. Simulations using the fully compressible nonhydrostatic LAM (D-NICAM) were compared against the corresponding global quasiuniform-grid Nonhydrostatic Icosahedral Atmospheric Model (NICAM) and a stretched-grid counterpart (S-NICAM). By this approach of sharing the same dynamical core and physical schemes, possible causes of model bias and LBC errors are isolated. The simulations were performed for a 395-day period from March 2011 through March 2012 with horizontal grid intervals of 14, 28, and $56 \mathrm{~km}$ in the region of interest. The resulting temporal mean statistics of the temperatures at $500 \mathrm{hPa}$ were generally well correlated between the global and regional simulations, indicating that LBC errors had a minor impact on the large-scale flows. However, the time-varying statistics of the surface precipitation showed that the LBC errors lead to the unpredictability of convective precipitation, which affected the mean statistics of the precipitation distributions but induced only minor influences on the large-scale systems. Specifically, extratropical cyclones and orographic precipitation are not severely affected. It was concluded that the errors of the precipitation distribution are not due to the difference of the model configurations but rather to the uncertainty of the system itself. This study suggests that applications of ensemble runs, internal nudging, or simulations with longer time scales are needed to obtain more statistically significant results of the precipitation distribution in regional climate models.
\end{abstract}

\section{Introduction}

In regional climate studies, nonhydrostatic, limitedarea atmospheric models are used to simulate shortand long-range numerical forecasts and detailed features of local meteorology (Skamarock et al. 2008; Lo et al. 2008; Sasaki et al. 2008); in those cases, high resolution is normally required to reproduce mesoscale flows and small-scale phenomena that are as important as large-scale flows in local climates. Such limited-area climate models (LAMs) often have resolutions of a few kilometers, wherein hydrostatic approximations are no longer applicable. In addition, their computational affordability compared to currently available highresolution nonhydrostatic global circulation models

Corresponding author: Junya Uchida, junya@aori.u-tokyo.ac.jp (global NHMs or nonhydrostatic GCMs) (Satoh et al. 2008, 2014; Putman and Suarez 2011; Skamarock et al. 2012) provides another reason for the common application of LAMs to, for instance, seasonal predictability studies (Ratnam et al. 2016), aerosol and chemical transport problems (e.g., Chapman et al. 2009), regional climate change projections (Ban et al. 2015), climate process studies (Ban et al. 2014; Fosser et al. 2015; Ratnam et al. 2015), and regional climate sensitivity studies with surface forcings from, for example, complex topographies (Hong and Lee 2009; Flesch and Reuter 2012).

LAMs solve boundary value problems, and external data, which are often derived from GCMs (of which global NHMs are a part), are forced at lateral boundaries (LBs); such a scheme is called dynamical downscaling because transferring large-scale synoptic flow 
information through lateral boundaries will generate smaller mesoscale flows inside the domains of finerresolution LAMs. Those small-scale flows enabled by the higher-resolution LAMs are thought to provide added value over the coarser-driving GCMs (Giorgi and Mearns 1991; 1999; Warner et al. 1997; McGregor 1997; Giorgi et al. 2001; Mearns et al. 2003; Leung et al. 2003; Wang et al. 2004; Laprise et al. 2008; Foley 2010; Feser et al. 2011; Mesinger et al. 2012; Flato et al. 2013; Prein et al. 2015).

Improvements are often seen at locations of complex topographies, for example, coastlines, mountains, and lakes, which are largely mesoscale features, and in higher-moment climate statistics, including extreme events and climate variability at regional scales (Wang et al. 2004; Prein et al. 2013a,b). On the other hand, it is expected that the amount of improvement is thought to be highly sensitive to the details of model configurations; these include one-way nesting strategies, for instance, domain sizes, placement of boundaries, differences in spatial and temporal resolutions used to compute the LAMs and the driving GCMs, representations of surface forcings such as vegetation schemes and complex topographies, and increased accuracies of dynamical and other physical processes in the LAMs, including convection and cloud microphysics (Leung and Ghan 1998; Laprise et al. 2008; Larsen et al. 2013). One complication is that LAMs add an extra error, which is attributed to the nesting strategy, referred to as lateral boundary condition (LBC) errors, in addition to model biases, which are indicators of the mean tendency of dynamical or microphysical schemes that the models use and the errors due to unpredictability inherent in the climate system (which we refer to as stochastic errors). Furthermore, those factors are all intertwined, and it is highly difficult to quantify and differentiate the error components. Generally, LBC errors can be attributed to, for example, errors caused by poorer spatial or temporal resolution data at boundaries, horizontal and vertical interpolation errors, inconsistencies in dynamical or other physical processes that are used in regional models and their driving models, and reflections of inertia-gravity waves at lateral boundaries (Warner et al. 1997; Giorgi and Mearns 1999; Denis et al. 2002). To address such errors, multiple nesting techniques, the application of relaxation and smoothing methods over regions bordering the LB, and/or internal nudging techniques are used to diffuse or nudge the erroneous waves (Juang and Hong 2001; Rummukainen 2010).

Another type of regional climate model (RCM), nonhydrostatic variable-resolution GCMs (VRGCMs), is composed of global models that can concentrate horizontal grid points in regions of interest. An intended region would have finer resolution, whereas a distant region would result in coarser grid intervals to conserve computational resources. Compared to two-way nesting schemes of LAMs that generate discontinuities at the LB, far smoother transitions of atmospheric conditions between the multiple resolutions are expected without explicit LBC errors (Hashimoto et al. 2016). However, a lack of appropriately scale-aware parameterizations may result in different responses at varying resolutions (Zarzycki et al. 2014; Rauscher et al. 2013; Sakaguchi et al. 2015) that set thresholds on the maximum stretching factors and grid intervals at antifocal points to control the degree of inaccuracies originating from the region of coarser grids without proper nudging techniques (Déqué and Piedelievre 1995; Caian and Geleyn 1997; Fox-Rabinovitz et al. 2006; Uchida et al. 2016).

To assess the uncertainties due to the downscaling abilities of LAMs, a "big-brother experiment" (BBE) was proposed to verify small-scale flows in LAMs (Denis et al. 2002; Denis et al. 2003; Dimitrijevic and Laprise 2005; Herceg et al. 2006; Antic et al. 2006; Køltzow et al. 2008; Matte et al. 2016). The idea was to create reference data by running a global high-resolution model and by filtering out small-scale information from the reference data; only the large-scale flows from a global highresolution model were used to drive the LAMs. It was therefore possible to validate the induced small-scale flows of LAMs against the small-scale flows of the reference dataset. However, because accessing such highresolution global models is difficult, the filtered results of large-domain LAMs were applied as LB data for the same LAMs with smaller-sized domains to determine the consistency of regional modeling, the process of which is termed a "poor man's" BBE. With the poor man's BBEs, however, a large-domain LAM is generally constrained by the GCMs of different physical processes used as LB data, and such results inherently contain the model tendencies of the driving GCMs. Our study differs from the poor man's BBE in that we compared the GCMs and LAMs of the same dynamical and physical processes, and the results of the GCMs were directly applied to the LAMs for the LBC data, taking advantage of the shared grid points over the regional domain. Using the nonhydrostatic GCMs and LAMs with no cumulus convective parameterizations, the shared grid formulations, and the same dynamical core and physical schemes to reduce model biases between the GCMs and LAMs, we were able to identify the primary processes that are highly sensitive to errors originating as small perturbations at boundaries and that propagate and grow within domains. In this study, we used the 
Nonhydrostatic Icosahedral Atmospheric Model (NICAM), which is a global cloud-system-resolving model (Tomita and Satoh 2004) that employs fully elastic equations, and a NICAM LAM mode called diamond-NICAM (D-NICAM). Another regional mode of a global stretchedgrid (SG) NICAM, a stretched-NICAM (S-NICAM), was also used as a reference to D-NICAM. In particular, because the model was nonhydrostatic and no cumulus parameterization was applied, we bypassed the issue of the size dependencies of convective parameterizations, which account for a major model bias factor (Déqué et al. 2007; Prein et al. 2015).

\section{Model description}

In this study, two types of global cloud-systemresolving models-NICAM and S-NICAM-and the corresponding "diamond NICAM" LAM (D-NICAM) were run for nearly 395 days from 1 March 2011 to 1 April 2012. The model settings were the same as those of Uchida et al. (2016) and were integrated with a single-moment microphysical parameterization scheme (Tomita 2008b), the mstrnX two-stream $k$-distribution radiative transfer code (Sekiguchi and Nakajima 2008) and an improved Mellor-Yamada level-2 turbulent closure model (Nakanishi and Niino 2004; Nakanishi and Niino 2009; Noda et al. 2010). The initial data were taken from the $1^{\circ} \times 1^{\circ}$ resolution National Centers for Environmental Prediction (NCEP) Final (FNL) Operational Global Analysis dataset, and for the surface boundary computations the Minimal Advanced Treatments of Surface Interaction and Runoff (MATSIRO; Takata et al. 2003) land surface models and a mixed layer ocean model, which was nudged toward the 6-hourly NCEP FNL SST data with a time scale of 7 days, were used. In addition, the CMIP3 model ensemble means of the monthly sea ice averaged over 1979-99 were used to compute the sea ice fractions and masses. All of the simulations were performed without any internal atmospheric relaxation. The 40 vertical levels were applied with the lowest few layers at $80.841,248.821,429.882$, and $625.045 \mathrm{~m}$, as measured from the surface up to the highest layer at $38113.969 \mathrm{~m}$, and the time steps for all of the runs were $15 \mathrm{~s}$. NICAM solves for the following variables: zonal velocity $u$, meridional velocity $v$, vertical velocity $w$, and thermodynamic variables of temperature $T$, pressure $P$, density $\rho$, water vapor $q_{v}$, cloud water $q_{c}$, cloud ice $q_{i}$, rainwater $q_{r}$, snow $q_{s}$, and graupel specific mass $q_{g}$.

The total number of NICAM horizontal grids was then controlled using a global level ( $g$ level), starting with an icosahedron-shaped object with a $g$ level of zero.
The horizontal length interval was then halved at each increment of the $g$ level using recursive mesh refinement processes that introduced new grids at the middle of two already existing grids (Tomita and Satoh 2004). For the study, we used a $g$-level 7 simulation $(\mathrm{g} 7)$ on a $56-\mathrm{km}$ quasi-homogenous mesh. At this scale, the simulations appear to be physically realistic even without a cumulus parameterization scheme, as our previous paper (Uchida et al. 2016) showed good agreement in the spatial pattern and general intensities of 90-day precipitation with TRMM satellite data.

S-NICAM, an SG model, applies a Schmidt transformation that concentrates the quasi-homogenous NICAM grids to the region of interest to create a gradual change in horizontal grid intervals from a fine mesh, at the focus, to a coarse mesh at the antifocal point (Tomita 2008a; Goto et al. 2015; Uchida et al. 2016), and the stretching factor is controlled by the stretching ratio ( $s$ ratio) parameter (Tomita 2008a), which represents the ratio of the smallest to largest horizontal grid intervals. We used $s$ ratios of 4 (g7-str4) and 16 (g7-str16), for which the error generated in the antifocal region is somewhat manageable (Uchida et al. 2016), applied to a g7 simulation centered at $41.90^{\circ} \mathrm{N}, 87.64^{\circ} \mathrm{W}$ (near Chicago, Illinois); $35.41^{\circ} \mathrm{N}, 140.00^{\circ} \mathrm{E}$ (over Japan); $48.58^{\circ} \mathrm{N}$, $2.27^{\circ} \mathrm{E}$ (over western Europe); and $15.00^{\circ} \mathrm{N}, 160.00^{\circ} \mathrm{W}$ (over the Pacific near Hawaii). The horizontal grid intervals ranged from $14 \mathrm{~km}(28 \mathrm{~km})$ at the focus to $223 \mathrm{~km}$ $(112 \mathrm{~km})$ at the antifocal point for the g7-str16 (g7-str4) simulations.

D-NICAM uses only 2 of an original 20 triangular panels that compose the initial icosahedron-shaped globe, which is composed of upside and downside equilateral triangles that create a rhombus- (or a diamond-) shaped domain. Therefore, when running an LAM mode, it uses approximately one-tenth of the total number of global grid points in addition to sharing all of the dynamical and other physical processes that NICAM implements. The prognostic variables, including $u, v, w, T, P, \rho, q_{v}$, and $q_{c}$, at three outermost grid points, are replaced with the external LB data at each time step in addition to the tendencies of the two outermost grids of the regional domain that are constantly set to zero. Because D-NICAM shares a section of the global NICAM grids, when a stretched-grid formulation of S-NICAM is applied to D-NICAM, its domain shrinks in accordance with the $s$ ratio, and applying a larger factor therefore results in a smaller-sized domain with a higher horizontal resolution. As a result, one platform can be applied to multiscale global (NICAM) and regional (D-NICAM) simulations, with stretched-grid models (S-NICAM) connecting those two scales. In this paper, we will 
directly compare D-NICAM results with the GCMs of the quasi-homogeneous NICAM and S-NICAM simulations for the nearly perfect references. Our aim is to isolate the LBC error by minimizing the many possible causes of model bias and LBC errors and analyze how the small continuous disturbances at the LB propagate and enhance the stochastic error and model bias in the domain. In other words, we quantify and analyze the possible processes between the different types of errors and discuss the uncertainties in LAMs that are not rooted in the physical parameterizations of the models.

\section{Model comparisons}

We compared several different sets of domain sizes and locations between the nonhydrostatic GCM and LAM runs with common grid formulations (illustrations are shown in Fig. 1) and dynamical and other physical processes. Tables 1 and 2 (as well as Table 4 later) provide quick reference summaries for all the simulations, including information on the names of the simulations, $g$ levels, LB data and their update frequencies, horizontal resolutions, locations of the foci, and time steps.

\section{a. The effect of LBC temporal resolution error in 18-day simulations}

First, we prepared the GCM for the S-NICAM g7str4 simulation centered on the United States (g7-str4; Fig. 1b) to output prognostic variables $u, v, w, T, P$, $\rho, q_{v}$, and $q_{c}$ at each time step (every $15 \mathrm{~s}$ ) and then directly used them as the driving LB data for the D-NICAM g7-str4 LAM run (D-str4_15s; Fig. 1e); we regard the outputs as nearly perfect LB data (Table 1). The intent was to estimate a lower threshold of the error between D-NICAM and the GCM simulations by restricting the temporal resolution error of the LB data to be a minimum. Note that NICAM uses a third-order Runge-Kutta scheme that divides 15 -s time steps into three large sub-time steps and six small sub-time steps, and the tendency terms are added to the prognostic variables at every large sub-time step. In the outermost two-grid space, the tendency was consistently fixed to zero within the durations of all the sub-time steps, and some inconsistencies were therefore inevitable at the LB. Another D-NICAM simulation was conducted to examine the influence of low temporal resolution LB data by applying the 3-hourly average g7-str4 simulation results as the driving LB data, which we have designated D-str4_3h; therefore, D-NICAM reads the linearly interpolated 3-hourly g7-str4 results at every time step. For the comparison, we excluded the nine outermost grids along the LB as a relaxation zone. Figure 2 displays the instantaneous temperature distributions [Figs. 2(1a)-(1i)] and absolute temperature differences [Figs. 2(2a)-(2f)] at the $z=1306.565-\mathrm{m}$ surface for the first 80,160 , and 240 time steps. The temperature differences for both D-str4_15s and a D-str4_3h [Figs. 2(2a)-(2f)] indicate that the initial LBC error propagated gradually from the directions of all the outer boundaries toward the center; the rates of propagation were similar for both the D-str4_15s and D-str4_3h simulations, but the magnitude of its LBC error highly depended on other factors - in our case, a temporal interpolation error. The D-str4_15s simulation had the maximum RMSE between 0.007 and $0.008 \mathrm{~K}$, whereas D-str4_3h had the maximum value between 0.02 and $0.05 \mathrm{~K}$. Once the error covered the entire domain, the deviations tended to intensify at the locations of fast developing fronts and localized convection, which are frequently seen on the southeast coast along the Gulf of Mexico.

Figure 3 depicts the domain-average spatial RMSE time series plots of the horizontal velocities $u$ and $v$ and temperature $T$ for S-NICAM and D-NICAM, which updated the LB data at every time step (D-str4_15s; blue line) or every $3 \mathrm{~h}$ (D-str4_3h; red line) for 18 days from 0000 UTC 1 March through 0000 UTC 19 March 2011. The RMSEs of $T, u$, and $v$ are shown from the top to the bottom in Fig. 3; the left column is for the $z=1306.565-\mathrm{m}$ surface, and the right is for the $z=6891.642-\mathrm{m}$ surface. As expected, all the RMSE time series were consistently smaller for the blue lines, except for a few sharp peaks along the lower-altitude $(z=1306.565 \mathrm{~m})$ (Figs. 3a,c,e) surface. The high-frequency spikes (of a few hours) were primarily related to local convection, and the low frequencies (of days) were related to the existence of fast-developing fronts. In addition, the RMSEs for both D-str4_15s and D-str4_3h followed similar trends in the locations of the larger peaks, which was especially true for the higher altitude $(z=6891.642 \mathrm{~m})$ (Figs. 3b,d,f) because the effects of large-scale extratropical cyclones dominated over local convection. In addition, these RMSEs were stable, and the errors were very manageable, even for the low temporal resolution case of D-str4_3h. In this respect, the reasonable temporal resolution of the LB data is unlikely to affect the system, except for its magnitude of error.

\section{b. The 395-day simulations over North America}

Following the idea of using the LB data updated every $3 \mathrm{~h}$, we compared a 395-day-long simulation from 0000 UTC 1 March 2011 through 0000 UTC 1 April 2012 for a D-NICAM and a GCM 
(a) Global quasi-uniform grids (N. America)

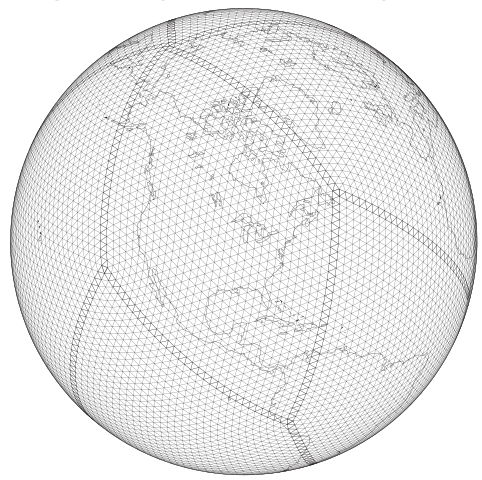

(d)

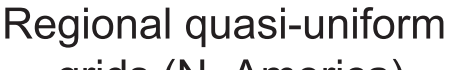
grids (N. America)

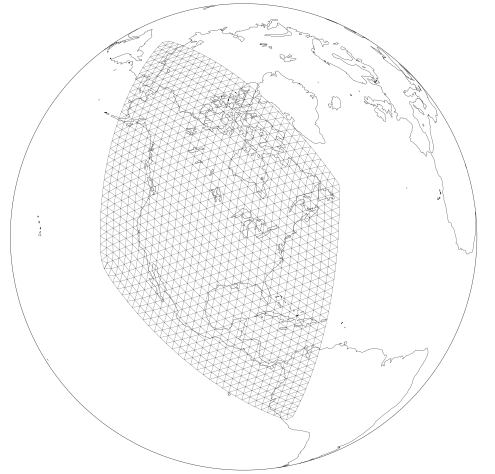

(g) Regional stretched grids

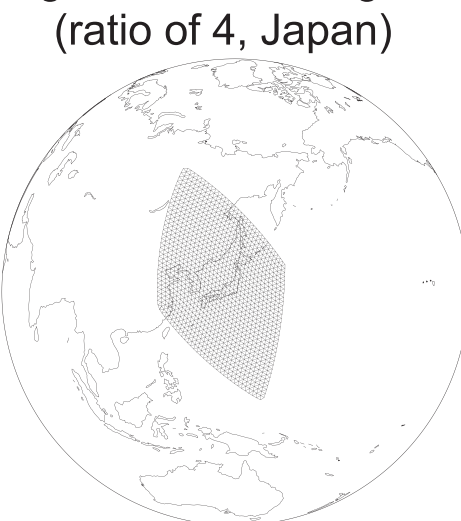

(b) Global stretched grids (ratio of 4)

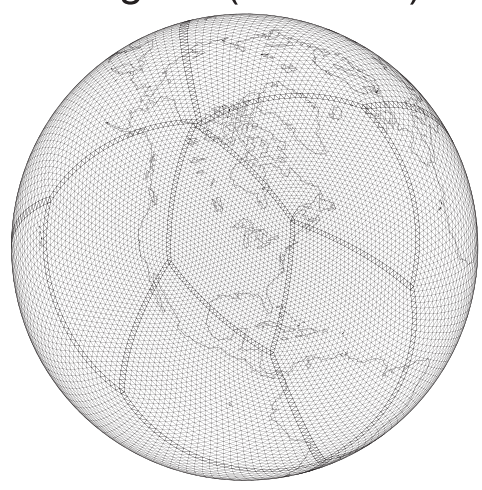

(e) Regional stretched grids (ratio of 4)

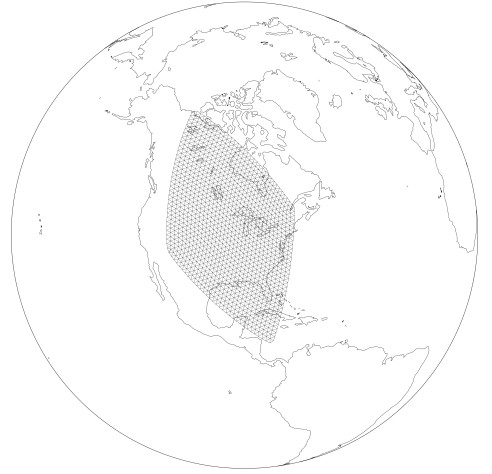

(h) Regional stretched grids (ratio of 4, Europe)

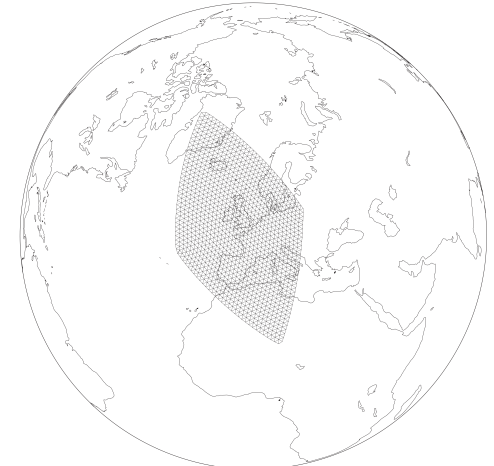

(c) Global stretched grids (ratio of 16)

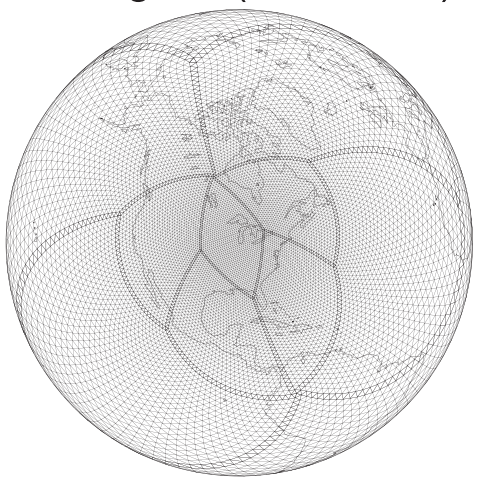

(f) Regional stretched grids (ratio of 16)

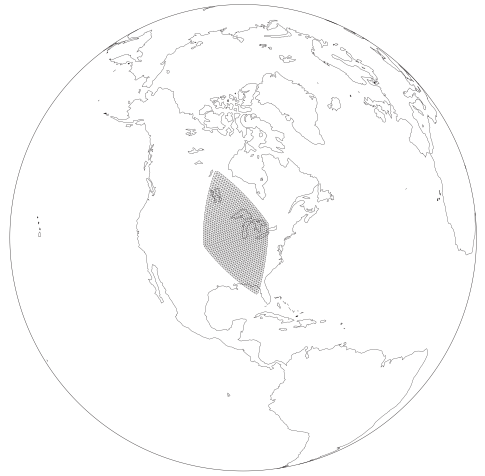

(i) Regional stretched grids (ratio of 4, the Pacific)

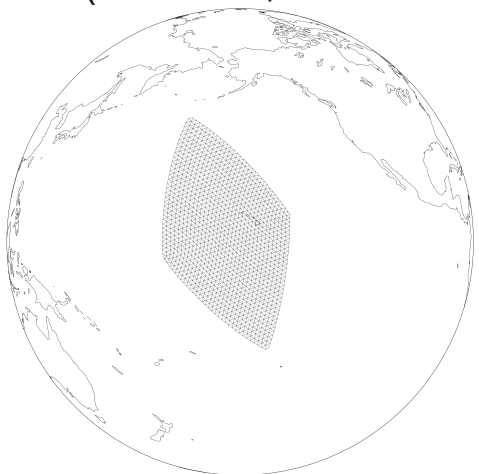

FIG. 1. Quasi-homogenous and stretched grids of the global and regional models are drawn over the globe. Adjacent grid points are connected for clarity. For the global simulations, we show (a) the g5 (we used g7 grids in the paper, with an additional three grid points between two adjacent grids) NICAM quasi-homogenous grids; (b) the g5 S-NICAM stretched ( $s$ ratio of 4) grids; and (c) the g5 S-NICAM ( $s$ ratio of 16) grids, centered on North America. The corresponding regional LAMs included three simulations: (d) the g5 D-NICAM quasihomogenous grids, (e) the g5 D-NICAM stretched ( $s$ ratio of 4$)$ grids, and (f) the g5 D-NICAM stretched ( $s$ ratio of 16) grids. Also shown is a regional LAM of the g5 D-NICAM stretched ( $s$ ratio of 4$)$ grids $(g)$ centered over Japan, $(\mathrm{h})$ western Europe, and (i) the Pacific near HI.

NICAM with several domain sizes (Table 2; Figs. 1a-f). For the global simulations, S-NICAM simulations with $s$ ratios of $16(\mathrm{~g} 7$-str16) and $4(\mathrm{~g} 7-\mathrm{str} 4)$ and the quasi-homogenous NICAM (g7) centered at $41.90^{\circ} \mathrm{N}$, $87.64^{\circ} \mathrm{W}$, near Chicago, were executed (Figs. 1a-c). Then, by directly applying their 3-h-averaged results as the driving LB data, corresponding regional D-NICAM simulations of three different sizes-D-str16, D-str4, 
TABLE 1. A lookup table for the model configurations: name, type (either global or regional simulations), update frequency of the LB data, focal point for the stretched grid, horizontal resolution, time step, and integration period for the 18-day simulations over the United States.

\begin{tabular}{lcccc}
\hline \hline \multicolumn{1}{c}{ Simulation $(\mathrm{g}$ level $)$} & $\mathrm{g} 7$-str4_15s $(\mathrm{g} 7)$ & D-str4_15s $(\mathrm{g} 7)$ & $\mathrm{g}$ 7-str4_3h $(\mathrm{g} 7)$ & D-str4_3h $(\mathrm{g} 7)$ \\
\hline Global or regional & Global & Regional & Global & Regional \\
LB data (update frequency) & - & g7-str4_15s (15 s) & - & g7-str4_3h (3h) \\
Stretched grid? & Yes & Yes & Yes & Yes \\
Focal point & $41.90^{\circ} \mathrm{N}, 87.64^{\circ} \mathrm{W}$ & $41.90^{\circ} \mathrm{N}, 87.64^{\circ} \mathrm{W}$ & $41.90^{\circ} \mathrm{N}, 87.64^{\circ} \mathrm{W}$ & $41.90^{\circ} \mathrm{N}, 87.64^{\circ} \mathrm{W}$ \\
Resolution $(\mathrm{km})$ & $28-112$ & 28 & $28-112$ & 28 \\
Time step (s) & 15 & 15 & 15 & 15 \\
Duration (days) & 18 & 18 & 18 & 18 \\
\hline
\end{tabular}

and D-g7 (Figs. 1d-f) -were integrated, and their results were compared. Within a regional domain, the horizontal resolutions were approximately 14 and $28 \mathrm{~km}$ for the ratios of 16 and 4, respectively, and the horizontal intervals of the quasi-homogenous $\mathrm{g} 7 \mathrm{grid}$ were approximately $56 \mathrm{~km}$. In addition, the results were linearly interpolated onto a $0.25^{\circ} \times 0.25^{\circ}$ resolution grid for the comparisons. We initially examined the model bias between D-NICAM and the global NICAM. In Fig. 4, the 395-day mean temperature biases [Figs. 4(1a)-(1c)], scatterplots of the mean $T$ [Figs. 4(2a)-(2c)], and the temporal RMSEs of $T$ [Figs. 4(3a)-(3c)] at $500 \mathrm{hPa}$ for the three sets of domain sizes of D-NICAM and the global NICAM are shown. The largest deviation in the model mean biases (in this case, the mean bias from the global simulations) was seen near the center of the domain and increased from $0.05 \mathrm{~K}$ to slightly less than $0.9 \mathrm{~K}$ as the size of the regional domain increased from the D-str16 [Fig. 4(1a)] to D-g7 [Fig. 4(1c)] simulations, although the bias was slightly tilted in the downwind direction for large-scale flows. This pattern implies that locations farther from the boundaries were less constrained by the given LB data and that large-scale flows can have greater leeway, as previously reported by Jones et al. (1995). Nevertheless, the bias was very minor, and the scatterplots [Figs. 4(2a)-(2c)] indicate that the correlations and regression lines were close to 1. In addition, the temporal RMSEs of the $500-\mathrm{hPa} T$ results [Figs. 4(3a)-(3c)] were similar to those shown in Figs. 4(1a)-(1c); the RMSE values increased toward the center of the domain and also increased with increasing domain size. The maximum RMSEs ranged from approximately $0.55 \mathrm{~K}$ for D-str16 [Fig. 4(3a)] to $1 \mathrm{~K}$ for D-str4 [Fig. 4(3b)] and $3 \mathrm{~K}$ for D-g7 [Fig. 4(3c)]. The implication is that a small perturbation caused by the LBC error gave rise to a generation of instantaneous stochastic errors that tended to be maximized at the center of the domain. Such instantaneous deviations, although much reduced when temporally averaged, affected the model bias, as the locations of the maximum errors were comparable, especially for the larger domain of D-g7. The correlations of the magnitudes of the mean temperature bias and the temporal temperature RMSEs at $500 \mathrm{hPa}$ were 0.395 , 0.561 , and 0.707 for D-str16, D-str4, and D-g7, respectively. Thus, higher correlations were seen as the domain size increased for a 500-hPa temperature, indicating that the deviations in the large-scale midlatitude eddies (extratropical cyclones) increased as the domain size expanded and became a dominant factor in producing the mean bias, while the small-scale flows of the chaotic convective motions dominated the deviations for the small domain of D-str16 that resulted in a low correlation.

Unlike the temperature distribution, it is difficult to match LAM and global model precipitation because precipitation is highly localized, and the end result involves complex cloud microphysics wherein large numbers of feedbacks are intertwined. Moreover, a

TABLE 2. As in Table 1, but for the 395-day simulations over the United States at three different domain sizes.

\begin{tabular}{lcccccc}
\hline \hline \multicolumn{1}{c}{ Simulation $(\mathrm{g}$ level $)$} & $\mathrm{g} 7(\mathrm{~g} 7)$ & $\mathrm{D}-\mathrm{g} 7(\mathrm{~g} 7)$ & $\mathrm{g} 7$-str4 $(\mathrm{g} 7)$ & $\mathrm{D}$-str4 $(\mathrm{g} 7)$ & $\mathrm{g} 7$-str16 $(\mathrm{g} 7)$ & $\mathrm{D}$-str16 $(\mathrm{g} 7)$ \\
\hline Global or regional & Global & Regional & Global & Regional & Global & Regional \\
LB data (update frequency) & - & $\mathrm{g} 7(3 \mathrm{~h})$ & - & $\mathrm{g} 7$-str4 $(3 \mathrm{~h})$ & - & $\mathrm{g} 7$-str16 $(3 \mathrm{~h})$ \\
Stretched grid? & No & No & Yes & Yes & Yes & Yes \\
Focal point & - & - & $41.90^{\circ} \mathrm{N}, 87.64^{\circ} \mathrm{W}$ & $41.90^{\circ} \mathrm{N}, 87.64^{\circ} \mathrm{W}$ & $41.90^{\circ} \mathrm{N}, 87.64^{\circ} \mathrm{W}$ & $41.90^{\circ} \mathrm{N}, 87.64^{\circ} \mathrm{W}$ \\
Resolution $(\mathrm{km})$ & 56 & 56 & $28-112$ & 28 & $14-224$ & 14 \\
Time step (s) & 15 & 15 & 15 & 15 & 15 & 395 \\
Duration (days) & 395 & 395 & 395 & 395 & 395 \\
\hline
\end{tabular}



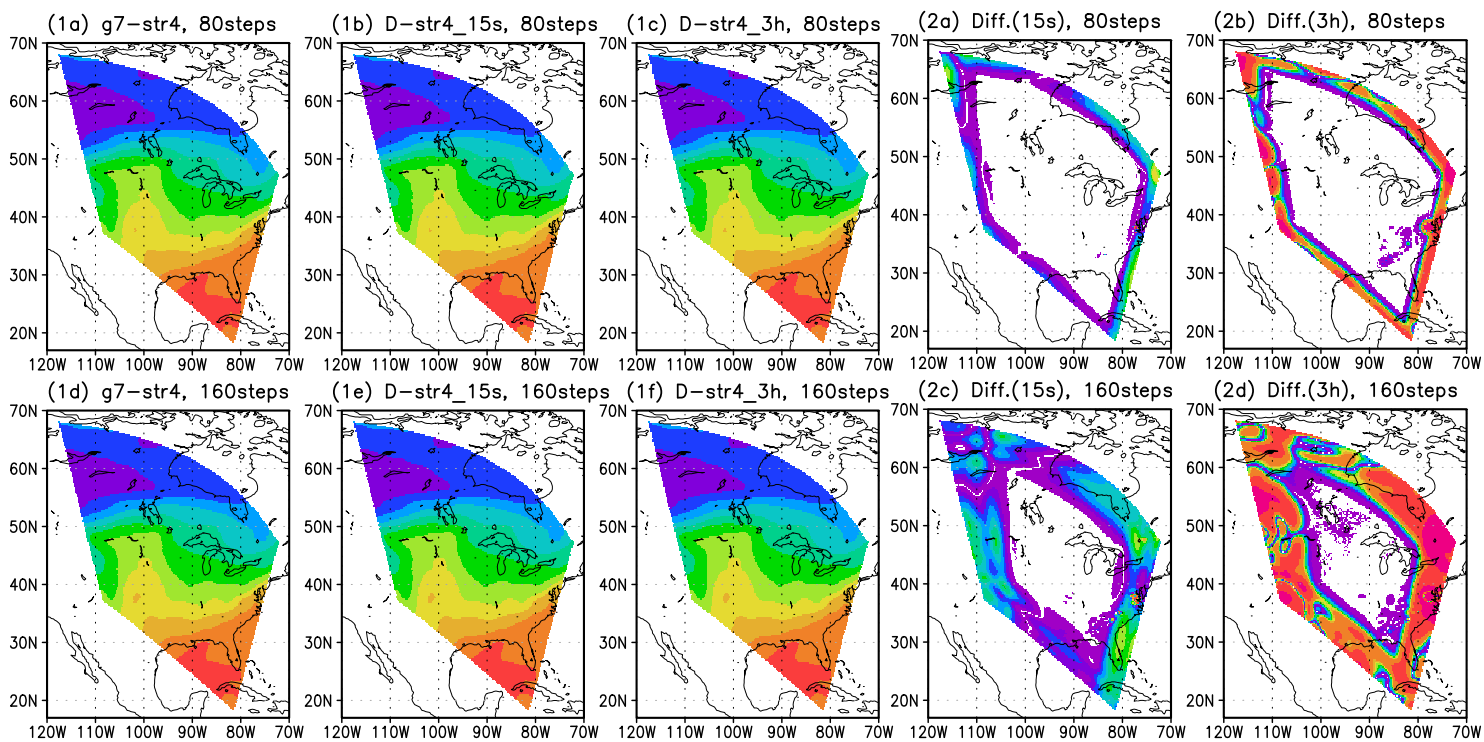

120W $110 \mathrm{~W}$ 100W 90W $80 \mathrm{~W}$
(2d) Diff.(3h), 160 steps
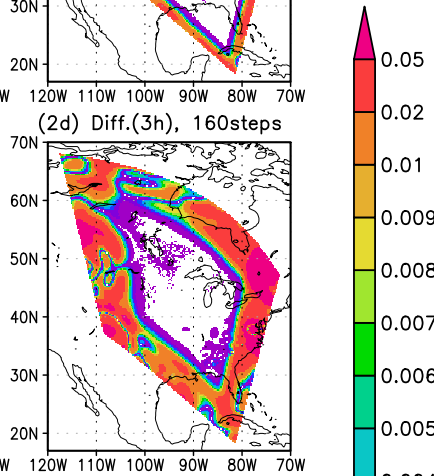

(1g) g7-str4, 240steps
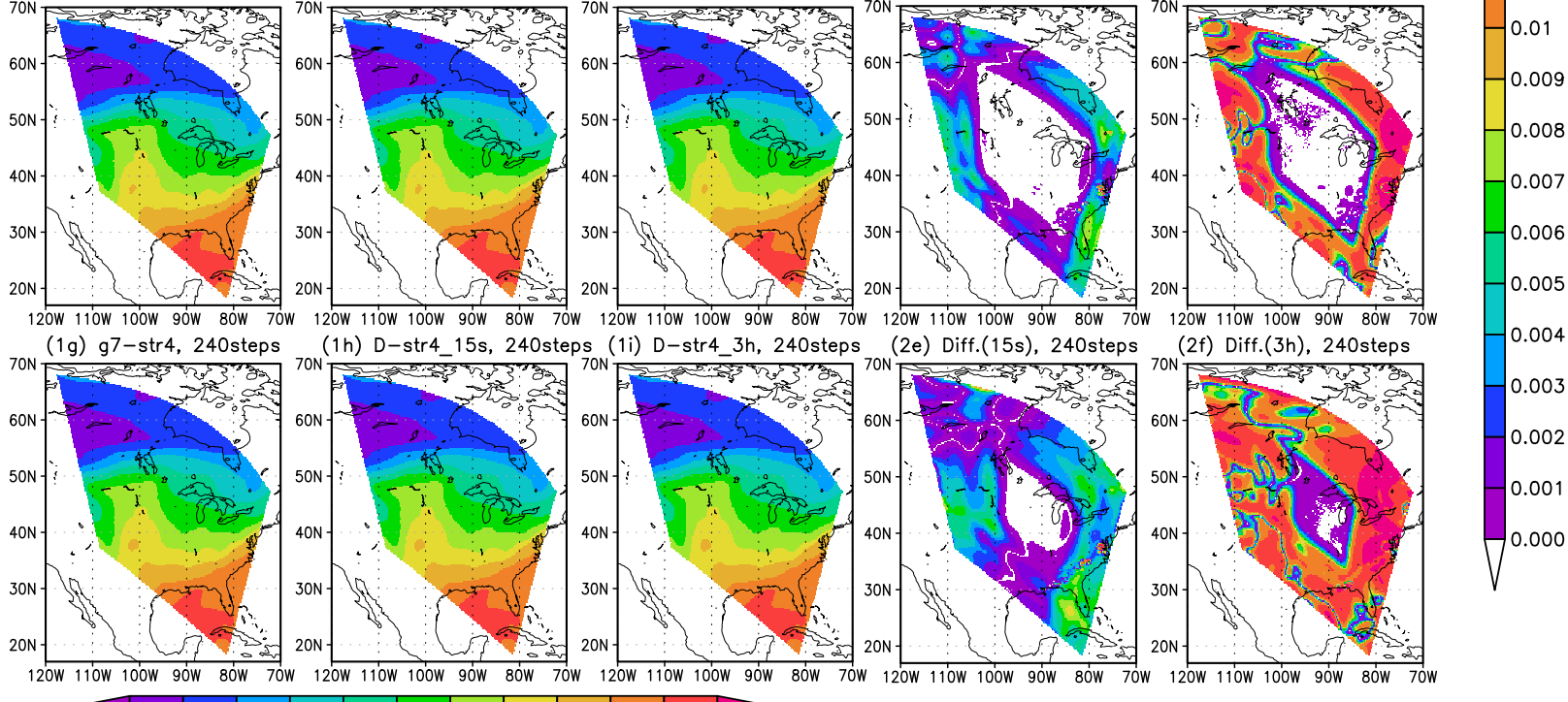

$\begin{array}{llllllllllll}240 & 245 & 250 & 255 & 260 & 265 & 270 & 275 & 280 & 285 & 290 & 295\end{array}$

FIG. 2. [(1a)-(1i)] Instantaneous temperatures and [(2a)-(2f)] magnitudes of the temperature differences (both in K) between the global and regional LAM models at the $z=1306.565$-m surface. (from top to bottom) Results for the first 80,160, and 240 time steps (15 s per time step). (from left to right) [(1a), (1d), (1g)] The global g7-str4 simulation, [(1b), (1e), (1h)] the regional D-str4 using 15-s updated LB data (D-str4_15s), [(1c), (1f), (1i)] D-str4 with every 3-h updated LB data (D-str4_3h), and the absolute differences between [(2a), (2c), (2e)] g7-str4 and D-str4_15s and [(2b), (2d), (2f)] g7-str4 and str4_3h.

rainwater variable is not explicitly given at the boundary. Nevertheless, obtaining accurate surface precipitation distributions is a highly important factor in regional climate models. Figure 5 depicts the 395-day mean surface precipitation over the regional domain. Large amounts of precipitation were consistently seen in the southeastern United States for all of the simulations and in the Pacific Northwest and Central America for the largest domain [Figs. 5(1e),(1f)]. Although not shown, the fact that larger mean precipitation biases were observed at locations over the southeastern United States and Central America, but not in the Pacific Northwest, is indicative of the highly chaotic nature of convective precipitation and tropical cyclones compared to orographic precipitation. The correlations and regression lines [Figs. 5(2a)-(2c)] had values exceeding 0.9 for all cases, and the largest domain of D-g7 had a better correlation than those of the other two smaller domains because of the inclusion of the northern low precipitable zone and orographic precipitation over the Pacific Northwest. In addition, stronger precipitation was observed in the lower half of the latitudes below $40^{\circ} \mathrm{N}$ (as indicated by the bluecolored plus signs) than that occurring at latitudes higher than $40^{\circ} \mathrm{N}$ (as indicated by the green-colored plus signs), and in particular for D-g7, the spread of the green crosses was clearly narrower because the orographic precipitation and extratropical cyclones were predominant in the region above $40^{\circ} \mathrm{N}$.

The seasonal variations are shown in Fig. 6, which displays scatterplots of the 1-month mean surface precipitation over the domain during the months of April (Figs. 6a-c), July (Figs. 6d-f), and January (Figs. 6g-i) for D-NICAM and the global NICAM. Although not shown, there was intense precipitation related to the convection that covered large portions of D-str16 and D-str4 in the summer month of July, and although the spatial distributions closely matched, with correlations 

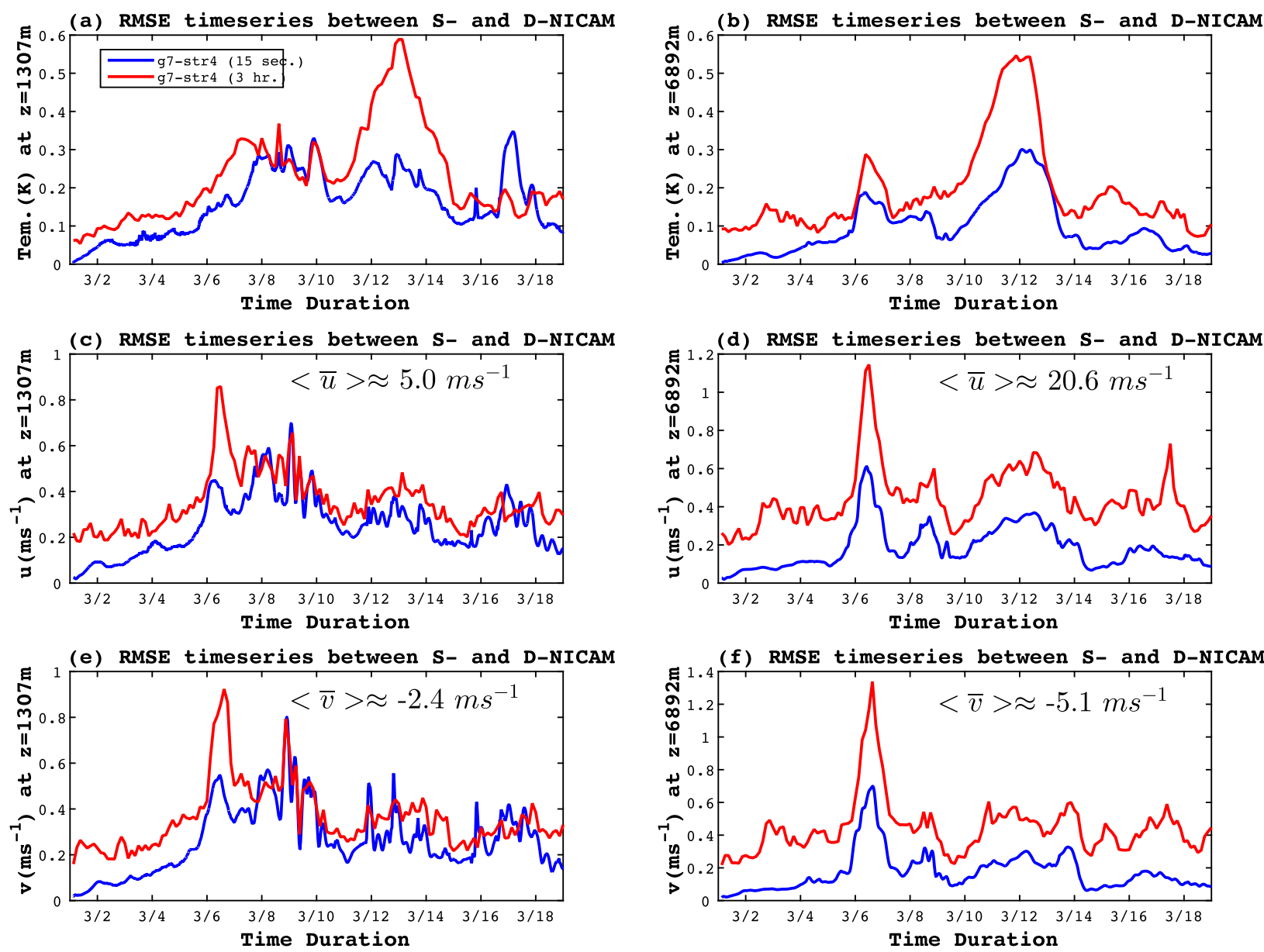

FIG. 3. Time series plots of the spatial RMSEs between the global S-NICAM model of g7-str4 and the regional LAM D-NICAM models of D7-str4_15s (blue lines) and D7-str4_3h (red lines). In addition, the RMSEs are shown for (a) temperature (in K) at $z=$ $1307 \mathrm{~m}$, (b) temperature at $z=6892 \mathrm{~m}$, (c) velocity $u\left(\mathrm{~m} \mathrm{~s}^{-1}\right)$ at $z=1307 \mathrm{~m},(\mathrm{~d}) u\left(\mathrm{~m} \mathrm{~s}^{-1}\right)$ at $z=6892 \mathrm{~m}$, (e) velocity $v\left(\mathrm{~m} \mathrm{~s}{ }^{-1}\right)$ at $z=$ $1307 \mathrm{~m}$, and (f) $v\left(\mathrm{~m} \mathrm{~s}^{-1}\right)$ at $z=6892 \mathrm{~m}$. The time and domain-average velocities $u$ and $v$, respectively, are displayed in the top-right corners of (c)-(f).

between 0.79 and 0.89 (Figs. $6 \mathrm{~d}-\mathrm{f}$ ), they were not as good as in the other seasons, implying the difficulty in reproducing the convective precipitation. By contrast, high correlations, exceeding 0.9 , were seen for the months of April and January, during which the extratropical precipitation predominantly covered the domains of D-str16 and D-str4, as the spreads of the green (latitudes lower than $40^{\circ} \mathrm{N}$ ) and blue (latitudes higher than $40^{\circ} \mathrm{N}$ ) dots were similar. For D-g7, the blue dots had a much wider spread than the green dots during the months of April and January as a result of the inclusion of the tropics, which produces convective precipitation all year.

We examined the temporal mean statistics and identified a connection in the day-to-day stochastic error that generates the mean bias. For instance, the temporal mean statistics of a 500-hPa $T$ is predominantly affected by the day-to-day deviations of large-scale flows, and the mean biases of surface precipitation are strongly influenced by the small-scale convection. We will next quantify the day-to-day stochastic error itself. Figures 7(1a)-(1c) show time series plots of the domainaveraged 3-hourly temperatures at $500 \mathrm{hPa}$ for the three different regional domain sizes-D-str16, D-str4, and D-g7-as red lines and the corresponding global runs as blue lines. All the runs had domain-average temporal correlations of nearly 1 , and the values slightly improved as the size of the domain declined. For the smallest domain of D-str16 [Fig. 7(1a)], a red line nearly overlaps the blue line, with a high correlation of 0.99995 , from which it can be assumed that the domain-average temperature was mostly restricted by the driving LB data, and less space was available for any errors from the large-scale flows to grow. For the largest domain of D-g7 

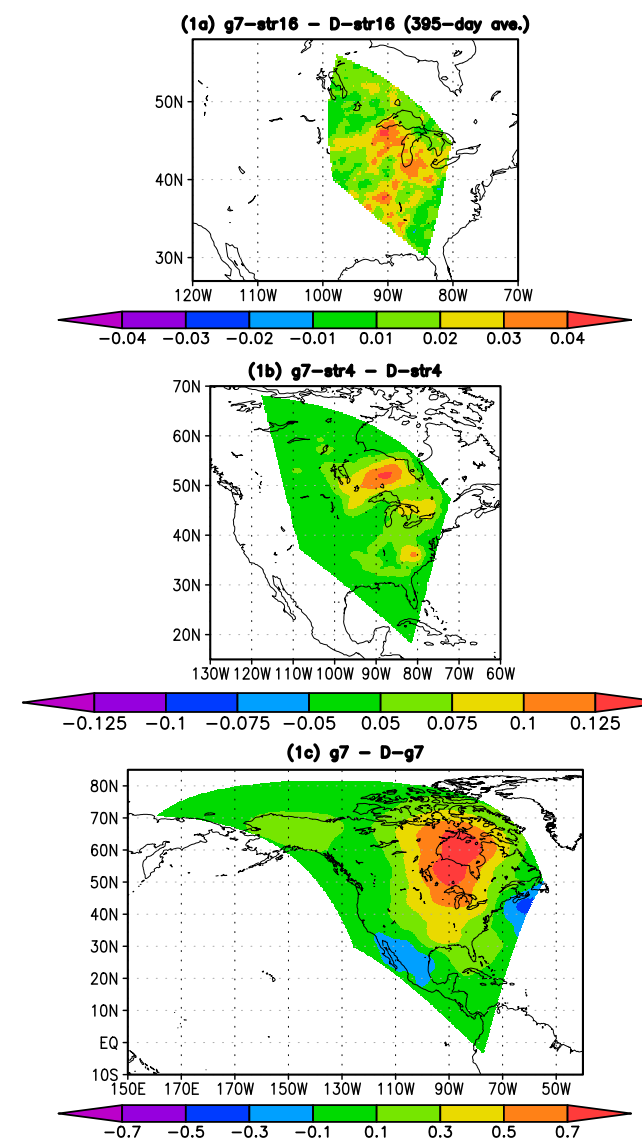

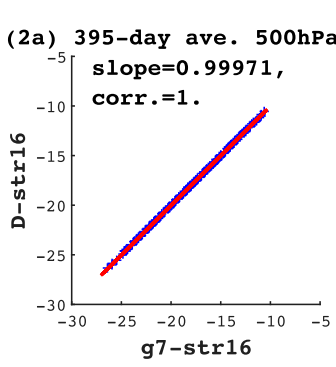

2b) Scatter plot
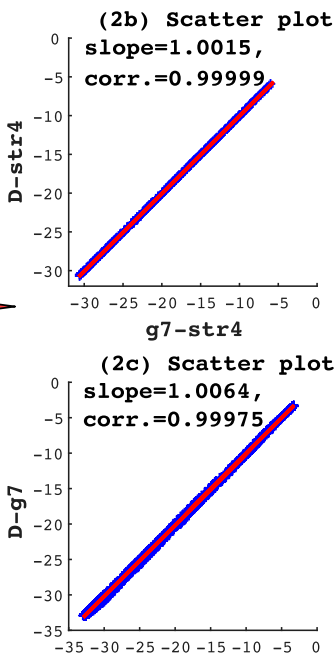

g7
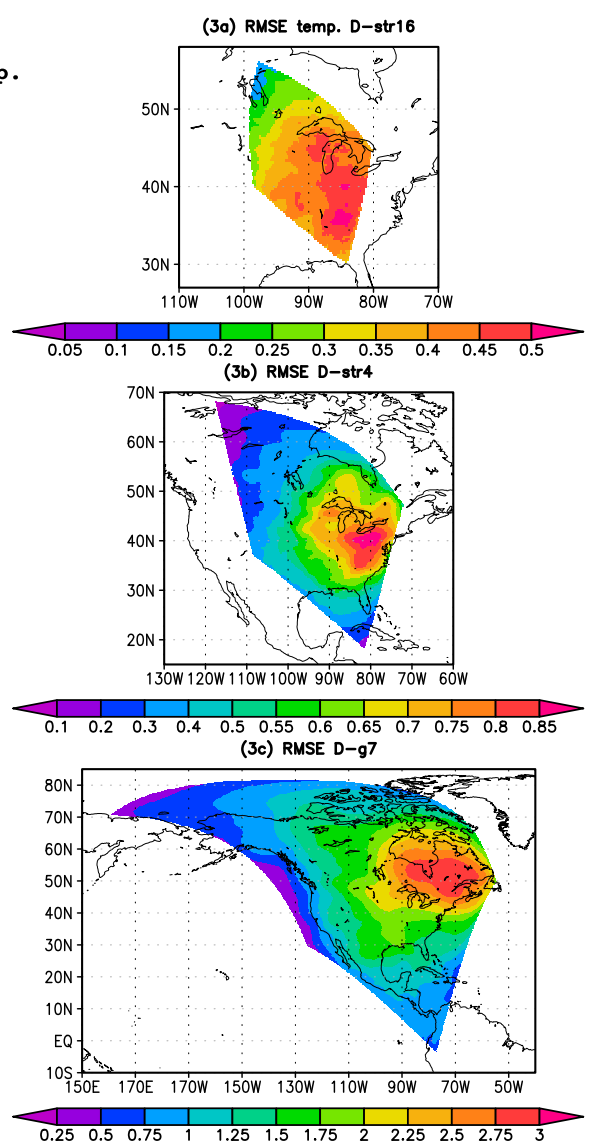

FIG. 4. The plots of 395-day (from 0000 UTC 1 Mar 2011 to 0000 UTC 1 Apr 2012) mean temperature statistics (in K) between the global NICAM and regional D-NICAM. (left) The 395-day mean temperature biases at $500 \mathrm{hPa}$ between (1a) g7-str16 and D-str16, (1b) g7-str4 and D-str4, and (1c) g7 and D-g7. (middle) Scatterplots of the 395-day mean temperatures at $500 \mathrm{hPa}$ between (2a) g7-str16 and D-str16, (2b) g7-str4 and D-str4, and (2c) g7 and D-g7. The blue dots were taken from every 21 st grid of the $0.25^{\circ} \times 0.25^{\circ}$ latitudelongitude grids, and the red lines are the lines of regression. The regression values (slopes) and the correlations are shown in the topleft corners of the panels. (right) Temporal RMSE temperatures at $500 \mathrm{hPa}$ between (3a) g7-str16 and D-str16, (3b) g7-str4 and D-str4, and $(3 \mathrm{c}) \mathrm{g} 7$ and D-g7

[Fig. 7(1c)], although it had a correlation that exceeded 0.99 , the larger region of leeway from the driving LB data allowed slightly more deviations from the global simulations. Figure 7(1d) displays temperature spatial RMSE time series plots, in which seasonal variations are seen as the deviations intensified during the summer, from May through October, compared to the other seasons for the D-str16 (blue line) and D-str4 (red line) runs because of strong local convective flows. However, the D-g7 case displayed discrepancies even in the winter season, and the seasonal variations were more difficult to identify because the frequent winter extratropical cyclones that developed within the large domain were not perfectly reproduced, whereas the smaller domains of D-str16 and D-str4 could only contain part of the winter extratropical cyclones that were not fully developed. In that respect, the seasonal variations seen for the spatial RMSE temperatures at $500 \mathrm{hPa}$ for the D-str4 and D-str16 runs were the product of systematic errors caused by local convections, while in the case of D-g7, another issue exists with the domain size, such that the large-scale flows were not fully reproduced. Figures 7(2a)-(2i) display time series plots of domain-averaged surface precipitation from the regional D-NICAM and the global simulations for daily [Figs. 7(2a),(2c),(2e)] and monthly [Figs. 7(2b),(2d),(2f)] rates. In addition, the spatial mean temporal correlations for the hourly, daily, weekly, and monthly precipitation rates are given in Table 3. The surface precipitation rates were well matched between the global and regional limited-area models, especially for D-str16 [Figs. 7(2a),(2b)], which had a temporal correlation that exceeded 0.95 for the hourly data and was even higher for the longer temporal averages (Table 3). Similar to the case of temperature, the precipitation rate was least matched during the summer [Figs. 7(2g),(2h)]; in part, the frequency and 
(10) g7-str16 (395-day ave.)

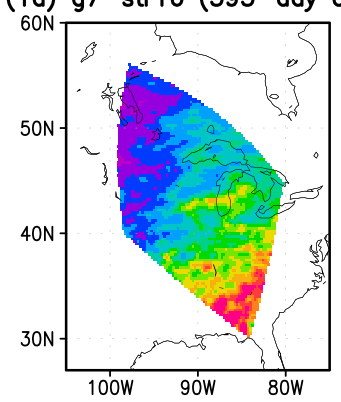

(1c) 97 -str 4

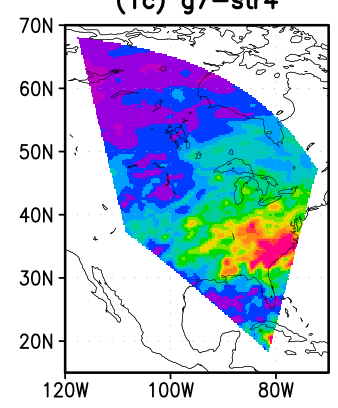

(1e) 97

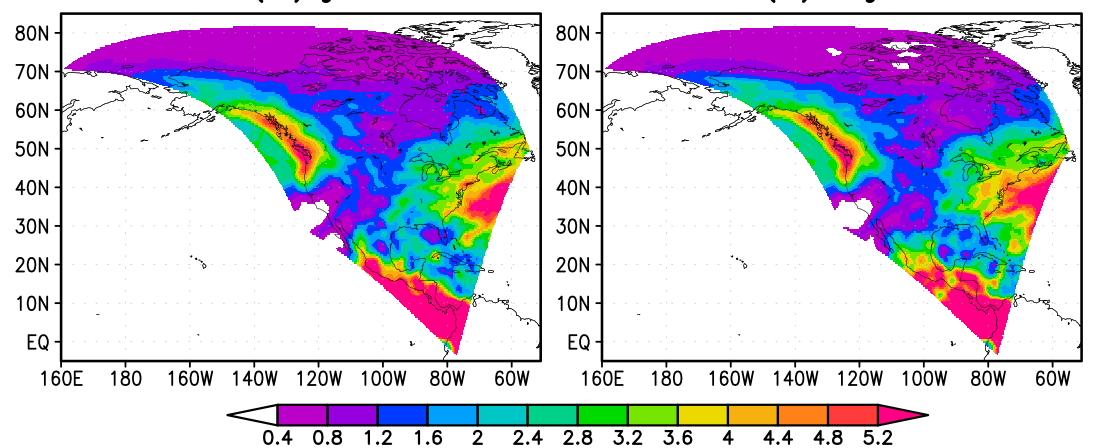

(1b) D-str 16

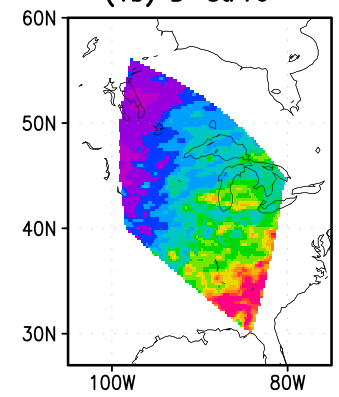

(1d) D-str4

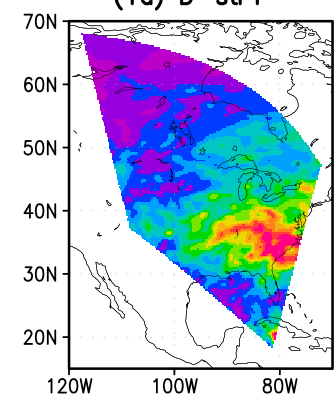

(1f) $D-g 7$

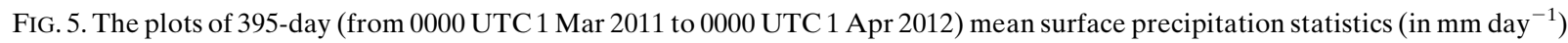
between the global NICAM and the regional D-NICAM. (leftmost two columns) The 395-day mean surface precipitation for (1a) the global g7-str16, (1b) the regional D-str16, (1c) g7-str4, (1d) D-str4, (1e) g7, and (1f) D-g7. (right) Scatterplots of the mean surface precipitation between (2a) g7-str16 and D-str16, (2b) g7-str4 and D-str4, and (2c) g7 and D-g7. The blue dots were taken from every fifth grid of the $0.25^{\circ} \times 0.25^{\circ}$ latitude-longitude grids below (equatorward) $40^{\circ} \mathrm{N}$, the green dots are higher (poleward) than $40^{\circ} \mathrm{N}$, and the red lines show the lines of regression of all the grids. The values of the slopes and correlations are displayed in the top-left corners of the panels.

intensity of the precipitation were higher, and the generation of summer convection and tropical cyclones was highly chaotic in nature. In addition, as in the case of temperature, a greater discrepancy was seen for the case of D-g7, as the correlation declined slightly as the domain size increased, but the values remained high, exceeding 0.8 for an hourly precipitation rate (Table 3). Instantaneous snapshots of the surface precipitation in summer, when convective precipitation is frequent, and in winter, when extratropical cyclones are easily identified, and the corresponding scatterplots are shown in Fig. 8. It is our understanding that day-to-day discrepancies in surface precipitation rates between global and regional limited area models are primarily caused by the stochastic nature of convective precipitation, which originates from small perturbations in the field. The scatterplots indicate exactly that, as the correlations are consistently low in Figs. 8(4a)-(4c), and it is difficult to replicate convective precipitation at any instant in time. In addition, the correlation of the extratropical cyclones was somewhat low for the D-g7 run because of slight deviations in the largescale flows [Fig. 8(4f)]. Eventually, those day-to-day deviations influenced the time mean tendencies in monthly (Fig. 6) and yearly (Fig. 5) precipitation. 

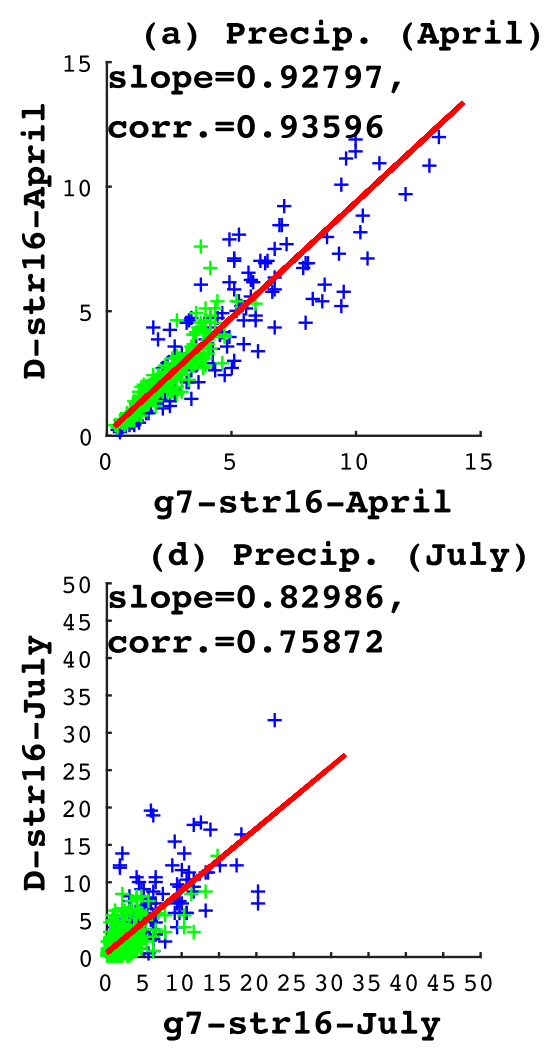

(g) Precip. (Jan)

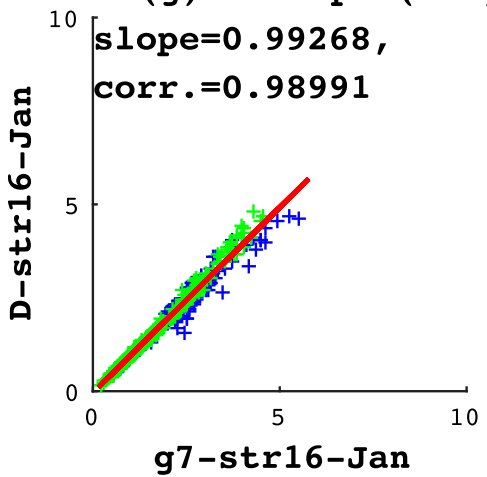

(b) Precip. (April)

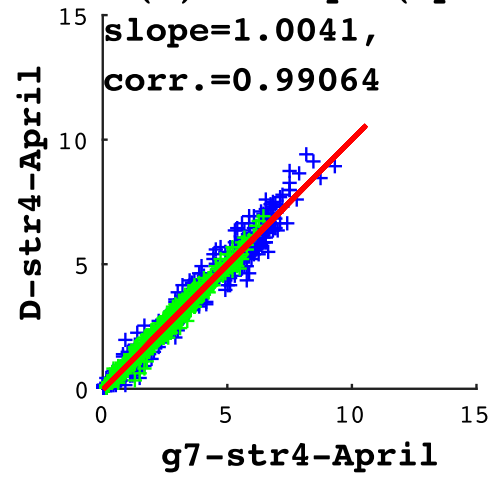

(e) Precip. (July)

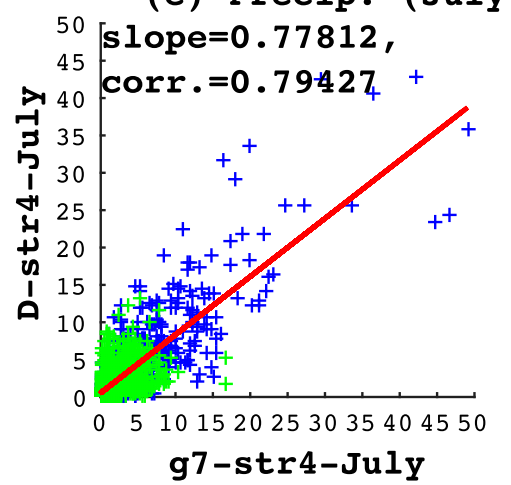

(h) Precip. (Jan)

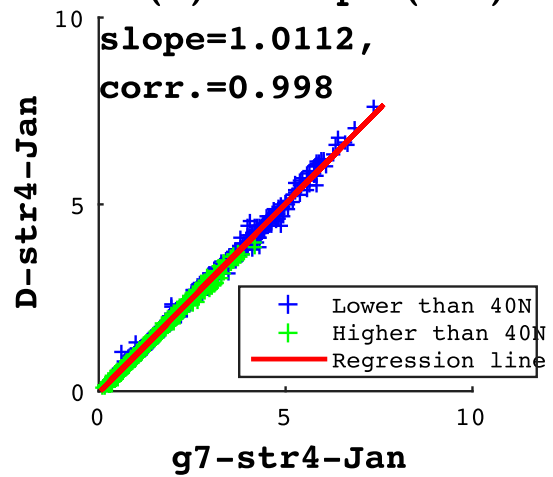

(c) Precip. (April)

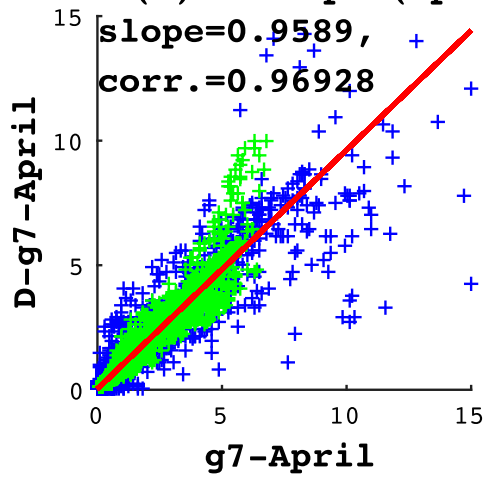

(f) Precip. (July)

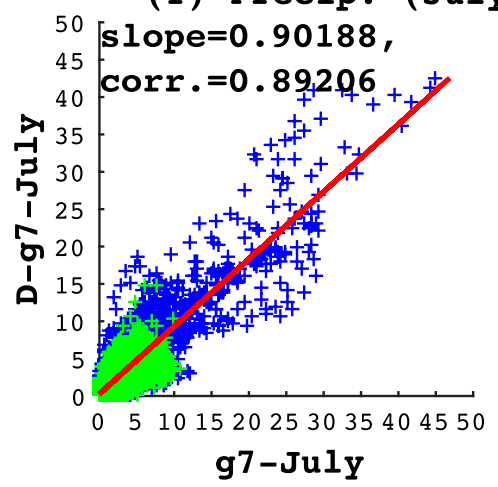

(i) Precip. (Jan)

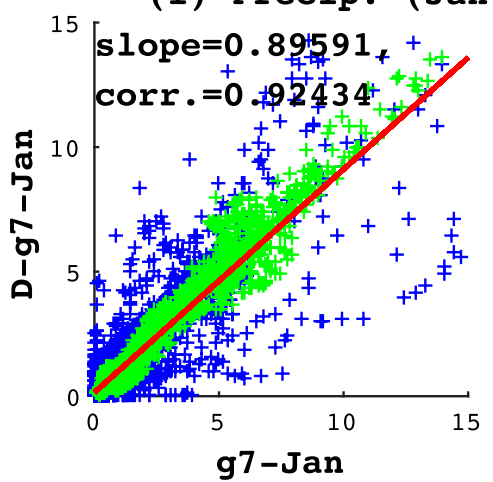

FIG. 6. Scatterplots of 1-month (April, July, and January) mean surface precipitation rates (in mm day ${ }^{-1}$ ) (a),(d),(g) between g7-str16 and D7-str16; (b),(e),(h) between g7-str4 and D7-str4, and (c),(f),(i) between g7 and D-g7. Every 12th grid of the $0.25^{\circ} \times 0.25^{\circ}$ latitudelongitude grids has been plotted using blue (lower than $40^{\circ} \mathrm{N}$ ) and green (higher than $40^{\circ} \mathrm{N}$ ) plus signs, and the red lines are the regression lines overlaid. The values of the regression lines and correlations are displayed in the top-left corners of the panels.

To quantify how closely the precipitation frequencies for D-NICAM and the global NICAM matched on each $0.25^{\circ} \times 0.25^{\circ}$ resolution latitude-longitude grid, the temporal correlations of the daily surface precipitation rates for the 3-month periods of spring [March-May 2011; Figs. 9(1a)-(1c)], summer [June-August 2011; Figs. 9(2a)-(2c)], fall [September-November 2011; Figs. 9(3a)-(3c)], and winter [December 2011-February 2012; Figs. 9(4a)-(4c)] were computed. Seasonal variations were clearly seen between the summer and winter periods. A region of high correlations that exceeded 0.9 was seen over a large part of the domain for the winter period, while a region of low correlations covered a major part of the domain in the summer, especially below $40^{\circ} \mathrm{N}$, where convective precipitation intensifies. In addition, as previously discussed, on the Pacific Northwest coast, where orographic precipitation often occurs during winter, a high value of temporal correlation was observed, while low correlations were seen in the tropics and downwind of the extratropical cyclones [Fig. 9(4c)]. 

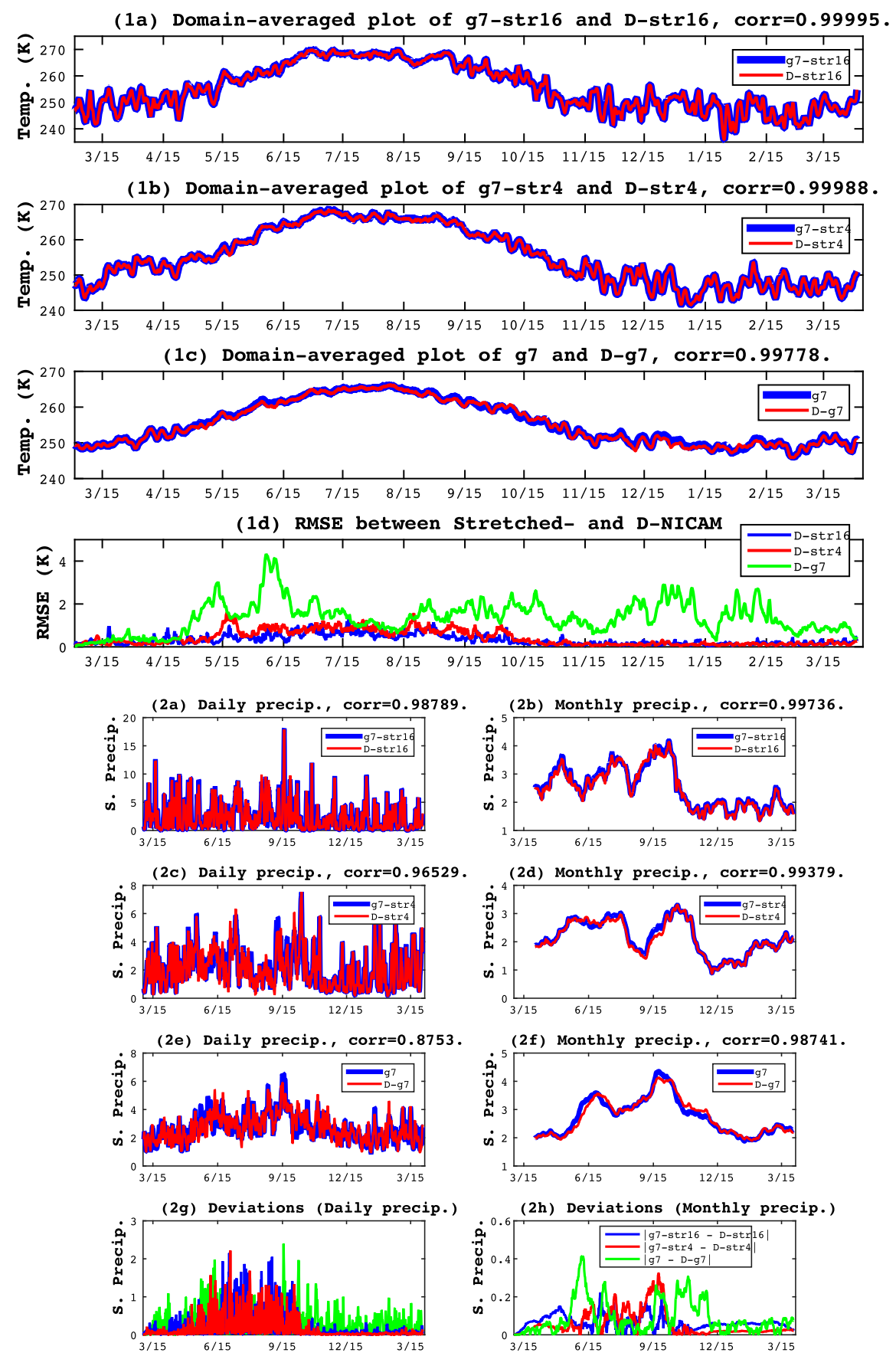

FIG. 7. Time series plots (from 0000 UTC 1 Mar 2011 to 0000 UTC 1 Apr 2012) of (1a)-(1c) the domain-average temperatures at $500 \mathrm{hPa}$ and (1d) spatial RMSE temperatures at $500 \mathrm{hPa}$. In (1a)-(1c) Blue lines are for the global simulations, and red lines are for the regional LAM simulations., and in (1d) the spatial RMSE temperatures of D-str16, D-str4, and D-g7 are shown using blue, red, and green lines, respectively. In addition, the temporal correlations of the domain-averaged temperatures at $500 \mathrm{hPa}$ are displayed in the titles in (1a)-(1c). (2a)-(2f) Time series plots of the domain-averaged surface precipitation (in mm day ${ }^{-1}$ ) are shown, and $(2 \mathrm{~g}),(2 \mathrm{~h})$ the magnitude differences of the domain-averaged surface precipitation between the global and LAM regional models are displayed. (left) The daily precipitation rates, and (right) the monthly precipitation rates, where the blue lines are for the global simulations and the red lines are for the regional LAM simulations. The temporal correlations of the domain-averaged surface precipitation are also displayed in the panel titles. In $(2 \mathrm{~g}),(2 \mathrm{~h})$ the absolute deviations in the domainaveraged surface precipitation for D7-str16, D7-str4, and D-g7 are represented by the blue, red, and green lines, respectively. 
TABLE 3. A lookup table of the temporal correlations of the domain-averaged surface precipitation. The hourly, weekly, and monthly precipitation correlations between the g7-str16, g7-str4, and D-g7 regional models and their corresponding global models are compared.

\begin{tabular}{ccccc}
\hline \hline Precipitation correlation & Hourly & Daily & Weekly & Monthly \\
\hline g7-str16 & 0.9570 & 0.9879 & 0.9940 & 0.9974 \\
g7-str4 & 0.9172 & 0.9653 & 0.9862 & 0.9938 \\
D-g7 & 0.8344 & 0.8753 & 0.9419 & 0.9874 \\
\hline
\end{tabular}

The resulting statistics seemed to favor the smaller domains as a result of the restrictions from the driving LB data, which influenced the larger portion of the domain; however, one downside is that insufficient downscaling results in a lack of smaller-scale flows. Figure 10 shows the energy spectra of the horizontal kinetic energies at $200 \mathrm{hPa}$ in the frequency domain for D-NICAM and the global NICAM. These spectra were computed by first removing the linear trends of the 3-hourly time series data of $u$ and $v$ on each $0.25^{\circ} \times 0.25^{\circ}$ resolution latitude-longitude grid, and the fast Fourier transform was then applied to compute the kinetic energy power spectra for each of the time series data, which were then spatially averaged. At a high frequency that exceeded once per day, larger amplitudes were observed for the smaller domains of higher-resolution runs as a result of a resolution dependency that produced small-scale flows, while at the low frequency, all the runs had similar spectra because the scales of the incoming flows were somewhat similar. At the same time, the largest deviations between D-NICAM and the global simulations were observed for the case of D-str16, with the smallest regional domain, as the discrepancies in the blue- and the cyan-colored lines were much greater than the discrepancies in either the red and magenta lines or the black and green lines at high frequencies. This pattern is characteristic of a smaller-sized domain that inhibits the sufficient creation of highfrequency flows, which are lost in low temporal resolution driving LB data. In addition, spikes at frequencies of twice per day appeared and were consistently observed in all the simulations. Matte et al. (2016) concluded that large-scale flows started to deviate when a regional square domain was adopted with a lateral dimension larger than about $2600 \mathrm{~km}$ while smallscale flows would not fully develop in a domain of lateral dimension smaller than $4300 \mathrm{~km}$, and such underestimation of a small-scale transient eddy was pronounced as the domain size decreased. Although this is not directly comparable to our results because of the differences in the model configurations, particularly in the shape of the computational domain, our results also exhibit a deviation of large-scale flow in the g7 simulation (a lateral dimension of the rhombus-shaped domain is about $7000 \mathrm{~km}$ ), as shown in Figs. 4 and 7 (1c). The amplitudes of the high-frequency (small scale) flows for the g7-str4 (an approximate lateral dimension of $3500 \mathrm{~km}$ ) and $\mathrm{g} 7$ simulations are slightly reduced, compared to their corresponding global simulations, and are more pronounced for the g7-str16 (an approximate lateral dimension of $1800 \mathrm{~km}$ ) simulation in Fig. 10. Our results are consistent with those of Matte et al. (2016) considering that the lateral dimension of an enclosed square region is smaller than (about $60 \%$ of) the lateral dimension of the rhombusshaped domain.

\section{c. The effect of different topography}

To consider the effects of the topographical dependence on the numerical error of the LAM simulations, we conducted simulations at three different locations centered over Japan, western Europe, and the Pacific (Figs. 1g-i). Each simulation was run for 395 days, as in the previous cases, and a stretching ratio of 4 was applied to minimize the deviations of large-scale flows. The global simulations were named g7-str4-Jp, g7-str4-Eu, and g7-str4-Pac for the foci centered over Japan, Europe, and the Pacific, respectively (Table 4). Similarly, the corresponding LAM simulations were named D-str4-Jp, D-str4-Eu, and D-str4-Pac in the same order. As before, 3-hourly results of the global simulations were directly used for the driving LB data for the D-NICAM simulations. The 395-day mean distributions of temperature and precipitation are plotted in Fig. 11. The scatterplots for the mean temperature [Figs. 11(1a)-(1c)] indicate values of nearly 1 for both the regressions and the correlations, implying that there were no visible temperature biases between the global and regional LAMs. In addition, Figs. 11(2a)-(2c) depict the temporal RMSE temperatures at $500 \mathrm{hPa}$, similar to Fig. 4, and maximum RMSEs are seen in the middle of the domain, with values of approximately $0.8,0.5$, and $1 \mathrm{~K}$ for D-str4-Jp, D-str4-Eu, and D-str4-Pac, respectively. The maximum RMSE in D-str4-Eu was tilted toward the continents, possibly as a result of summertime convection over land, while for D-str4-Pac, the maximum error was at the center because the ocean covered much of the domain, such that the underling topography did not affect the flow.

The distribution of the 395-day mean surface precipitation showed the intense observed precipitation for cases g7-str4-Jp and D-str4-Jp [Figs. 11(3a),(3b)] in the southeastern part of the domain, including Japan, where convective precipitation by the easterly trade winds and tropical cyclones may be factors. For cases g7-str4-Eu 

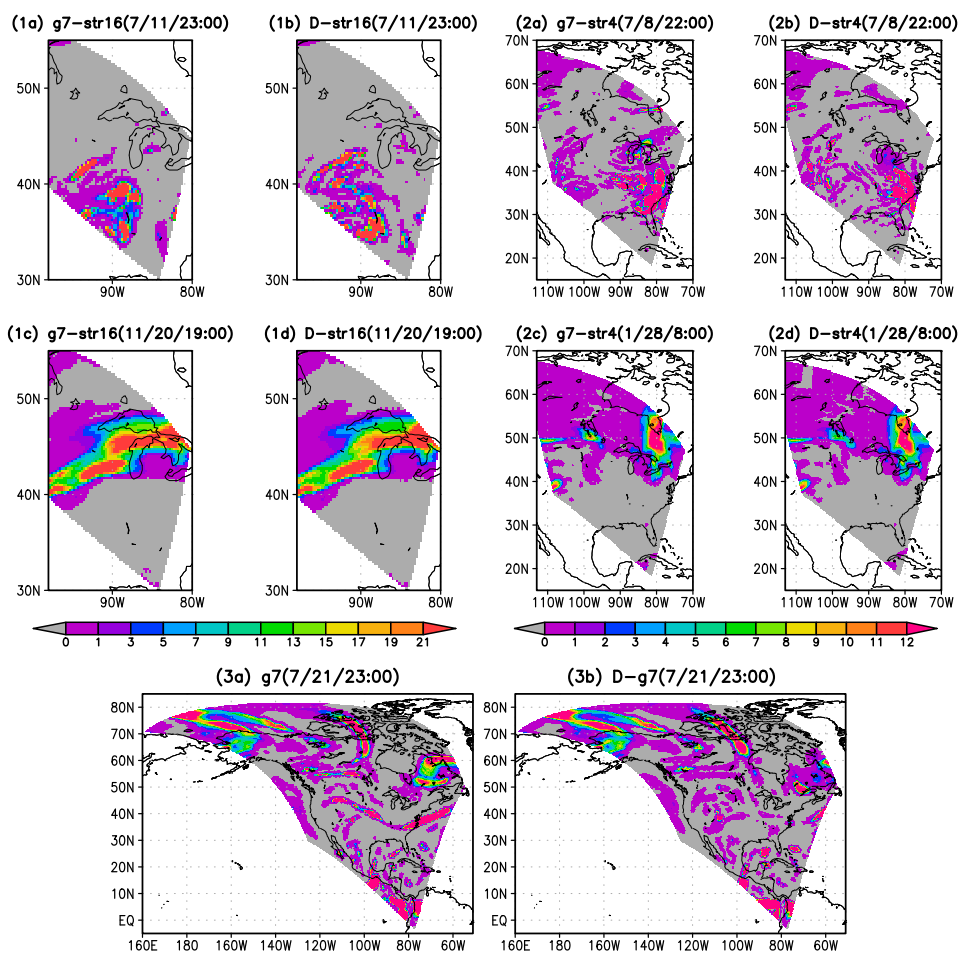

(3b) $D-g 7(7 / 21 / 23: 00)$

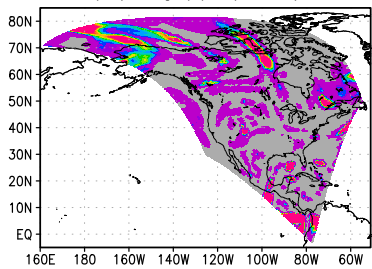

(3c) $g 7(12 / 17 / 16: 00)$

(3d) $D-g 7(12 / 17 / 16: 00)$
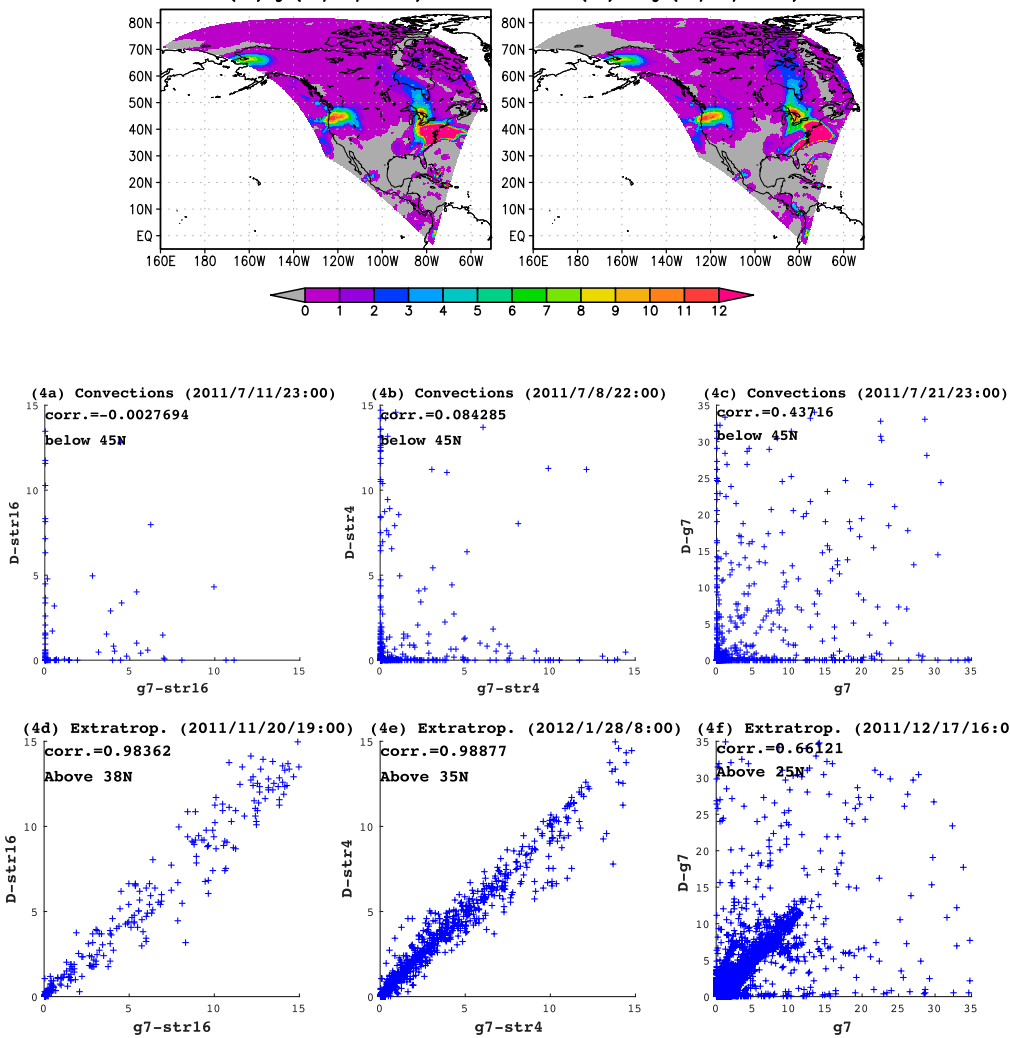

FIG. 8. A snapshot of the surface precipitation distributions $\left(\mathrm{mm} \mathrm{day}^{-1}\right)$ for summer and winter. The cases for (1a)-(1d) g7-str16 and D7-str16, (2a)-(2d) g7-str4 and D7-str4, and (3a)(3d) g7 and D-g7 are shown. In addition, shown are scatterplots for the instantaneous distributions of (4a)-(4c) the summer convection below $45^{\circ} \mathrm{N}$ and (4d)-(4f) extratropical cyclones. 


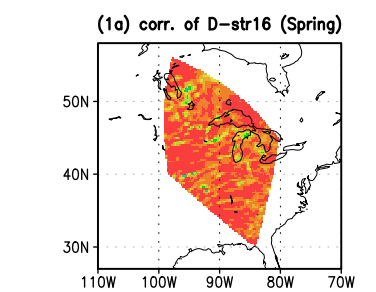

(1b) corr. of D-str4 (Spring)

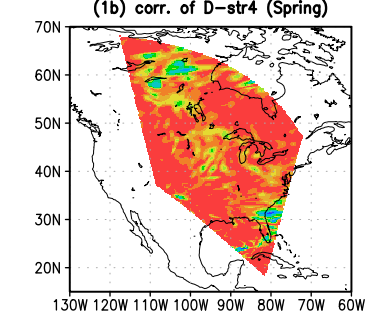

(1c) corr. of D-g7 (Spring)

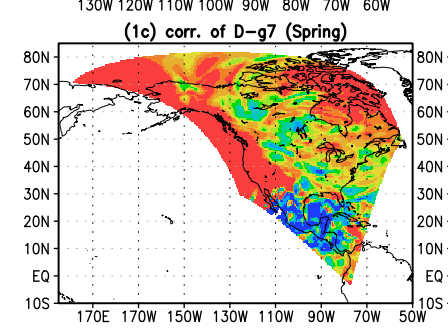

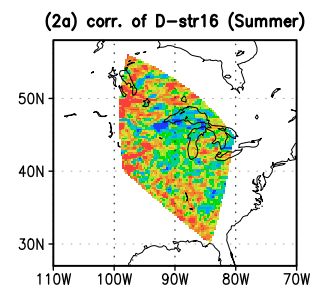

(2b) corr. of D-str4 (Summer)

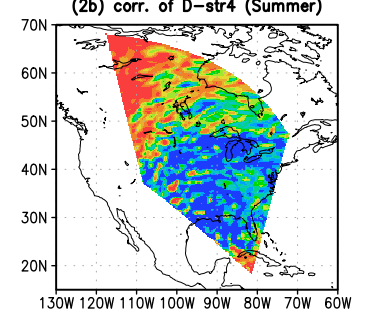

(2c) corr. of D-g7 (Summer) (3a) corr. of D-str16 (Fall)

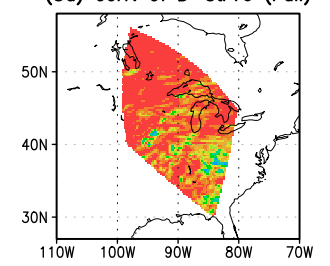

(3b) corr. of D-str4 (Fall)

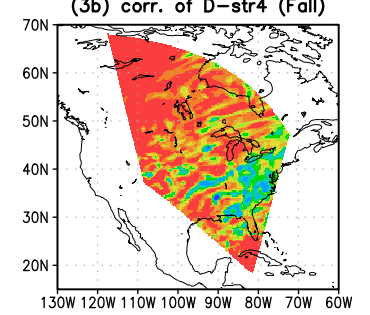

(3c) corr. of $\mathrm{D}-\mathrm{g} 7$ (Fall) (4a) corr. of D-str16 (Winter)

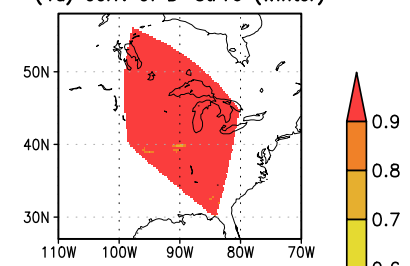

0.6

70N $\left.\frac{\text { (4b) corr. of D-str4 (Winter) }}{n}\right|_{0.5} ^{0.6}$
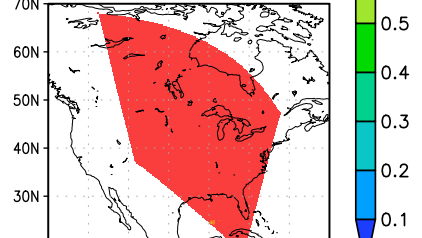

$20 \mathrm{~N}$

130W 120W 110W 100W gow sow $70 \mathrm{~W}$ 60W (4c) corr. of $D-g 7$ (Winter)

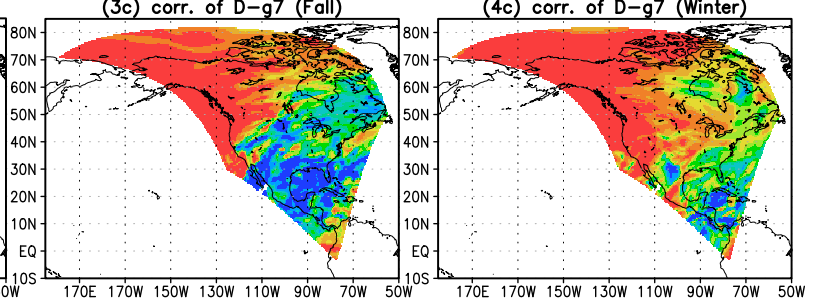

FIG. 9. The 3-month temporal correlations of daily surface precipitation. The temporal correlations were computed across four seasons: spring (March-May 2011), summer (June-August 2011), fall (September-November 2011), and winter (December 2011February 2012). (from top to bottom) Correlations of D-str16, D-str4, and D-g7 were calculated against the corresponding global models.

and D-str4-Eu [Figs. 11(3c),(3d)], intense precipitation was seen over the eastern part of the Scandinavian peninsula, the British Isles, and the adjacent Atlantic, caused by the extratropical cyclones, and orographic precipitation occurred in the Alps. Strong precipitation was simulated for cases g7-str4-Pac and D-str4-Pac [Figs. 11(3e),(3f)] across the ITCZ between the equator and $10^{\circ} \mathrm{N}$ and above $30^{\circ} \mathrm{N}$, where extratropical cyclones were observed. The scatterplots show a larger spread for D-str4-Pac [Fig. 11(4c)], which had a correlation (0.879) that was slightly lower than those in the other two simulations [Figs. 11(4a),(4b)], which had correlations exceeding 0.95 and regression lines of nearly 1 .

The temporal correlations of daily surface precipitation for the 3-month period, similar to Fig. 9, are shown in Fig. 12. Again, the same seasonal variation is obvious between the summer and winter periods for the D-str4-Jp and D-str4-Eu simulations, while D-str4-Pac showed no signs of seasonal variation because a majority of the domain covered the tropics and because convection related to the westward trade winds was a likely cause of the variation. The low correlation observed for D-str4-Eu in the summer was likely due to continental convective precipitation over the European continent and Mediterranean Sea [Fig. 12(2b)]. The instantaneous surface precipitation results for summer and winter are plotted in Fig. 13. For the simulations centered over Japan, the trade winds induced convective precipitation and tropical cyclones that covered the major part of the domain in summer, and extratropical cyclones were only seen in the section above $50^{\circ} \mathrm{N}$ [Figs. 13(1a),(1b)]. In winter, eastward extratropical cyclones were dominant in much of the domain above $20^{\circ} \mathrm{N}$. Similar to the previous cases of the North American simulations, convective precipitation and tropical cyclones of the small-scale flows had much lower correlations than the precipitation induced by the extratropical cyclones [Figs. 13(4a),(4d)]. For the simulations centered over western Europe, the precipitation caused by the extratropical cyclones covered the major part of the domain [Figs. 13(2c),(2d)], except in summer, when small-scale convection was seen mainly over the continent [Figs. 13(2a),(2b)]. For the simulations centered over the Pacific near Hawaii, trade winds induced convective precipitation over most of the domain [Figs. 13(3a),(3b)], except during the winter, when large-scale extratropical cyclones were seen above $30^{\circ} \mathrm{N}$ [Figs. 13(3c),(3d)]. All the LAM simulations consistently simulated the large-scale extratropical cyclones well [Figs. 13(4a)-(4c)] 


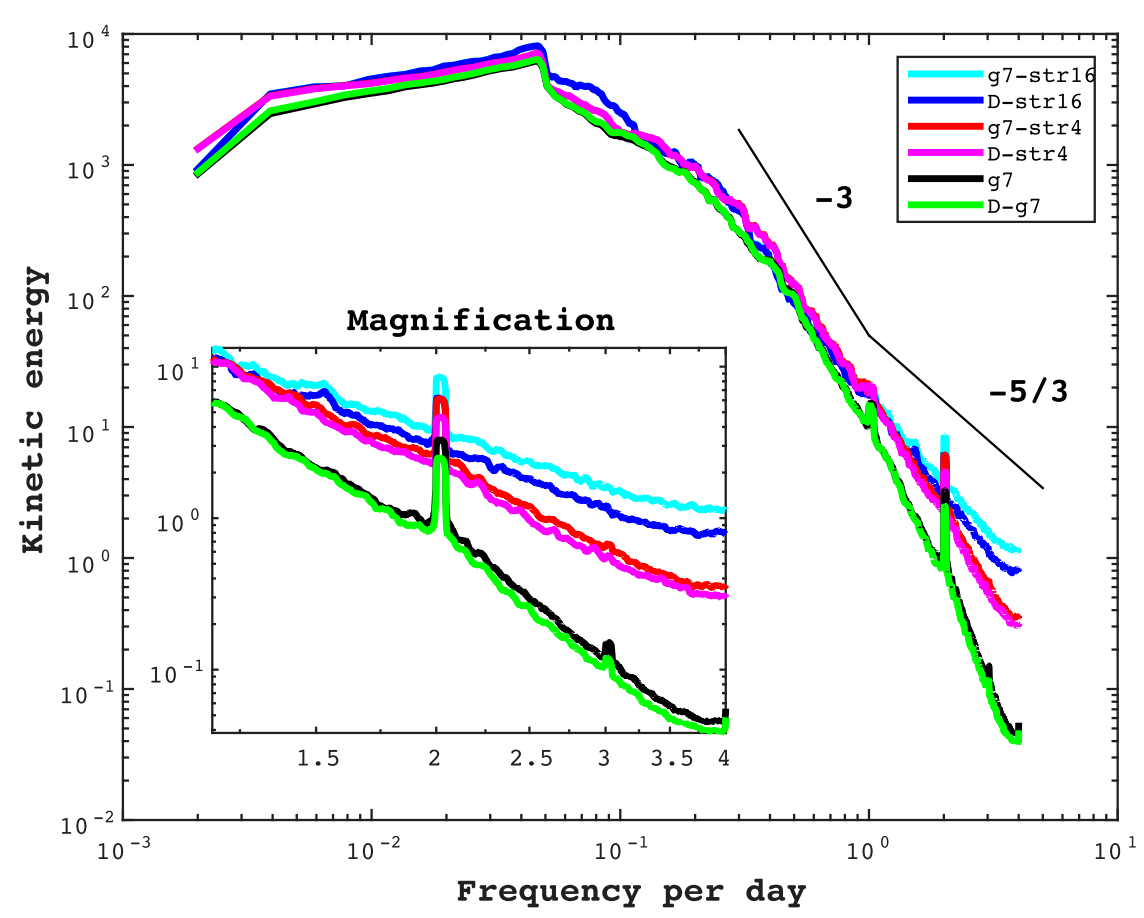

FIG. 10. The energy spectra of horizontal kinetic energies $\left(\mathrm{m}^{2} \mathrm{~s}^{-2}\right)$ at $200 \mathrm{hPa}$ in the frequency domain. The fast Fourier transforms of the 3-hourly time series data of $u$ and $v$ at each of the $0.25^{\circ} \times 0.25^{\circ}$ resolution latitude-longitude grids were domain averaged for g-str16 (cyan), D-str16 (blue), g-str4 (red), D-str4 (magenta), g7 (black), and D-g7 (green).

but had difficulty replicating the small-scale convection and tropical cyclones [Figs. 13(4d)-(4f)].

Figure 14 shows the time series plots of the domainaveraged 500-hPa temperatures and spatial RMSEs, similar to those shown in Fig. 7, but for the regions centered over Japan [Fig. 14(1a)], western Europe [Fig. 14(1b)], and the Pacific near Hawaii [Fig. 14(1c)]. The temporal correlations between the global and regional LAM simulations closely resembled one another [Figs. 14(1a)-(1c)], and it can be seen from the spatial RMSEs [Fig. 14(1d)] that the deviations were again greater during summer in comparison with the other seasons, except for D-str4-Pac, for which the RMSEs remained high throughout the year. Time series of the domain-averaged surface precipitation and absolute differences are plotted in Figs. 14(2a)-(2h), and the temporal correlations of the domain-averaged precipitation are listed in Table 5. Overall, all three simulations displayed high correlations for the weekly precipitation rates that exceeded 0.98. Among the three different locations, the least correlated run was for D-str4-Pac, for which the correlation for the hourly precipitation rate was 0.895 , while the other two runs had values that exceeded 0.95 . In particular, a high correlation value of 0.993 was observed for D-str4-Eu. In addition, D-str4-Eu was

TABLE 4. As in Table 1, but for the 395-day simulations over Japan, Europe, and the Pacific.

\begin{tabular}{|c|c|c|c|c|c|c|}
\hline Simulation ( $g$ level) & g7-str4-Jp (g7) & D-str4-Jp (g7) & g7-str4-Eu (g7) & D-str4-Eu (g7) & g7-str4-Pac (g7) & D-str4-Pac (g7) \\
\hline Global or regional & Global & Regional & Global & Regional & Global & Regional \\
\hline $\begin{array}{l}\text { LB data (update } \\
\text { frequency) }\end{array}$ & - & g7-str4-Jp (3h) & - & g7-str4-Eu (3h) & - & g7-str4-Pac (3h) \\
\hline Stretched grid? & Yes & Yes & Yes & Yes & Yes & Yes \\
\hline Focal point & $35.41^{\circ} \mathrm{N}, 140.00^{\circ} \mathrm{E}$ & $35.41^{\circ} \mathrm{N}, 140.00^{\circ} \mathrm{E}$ & $48.58^{\circ} \mathrm{N}, 2.27^{\circ} \mathrm{E}$ & $48.58^{\circ} \mathrm{N}, 2.27^{\circ} \mathrm{E}$ & $15.00^{\circ} \mathrm{N}, 160.00^{\circ} \mathrm{W}$ & $15.00^{\circ} \mathrm{N}, 160.00^{\circ} \mathrm{W}$ \\
\hline Resolution (km) & 28-112 & 28 & 28-112 & 28 & 28-112 & 28 \\
\hline Time step (s) & 15 & 15 & 15 & 15 & 15 & 15 \\
\hline Duration (days) & 395 & 395 & 395 & 395 & 395 & 395 \\
\hline
\end{tabular}



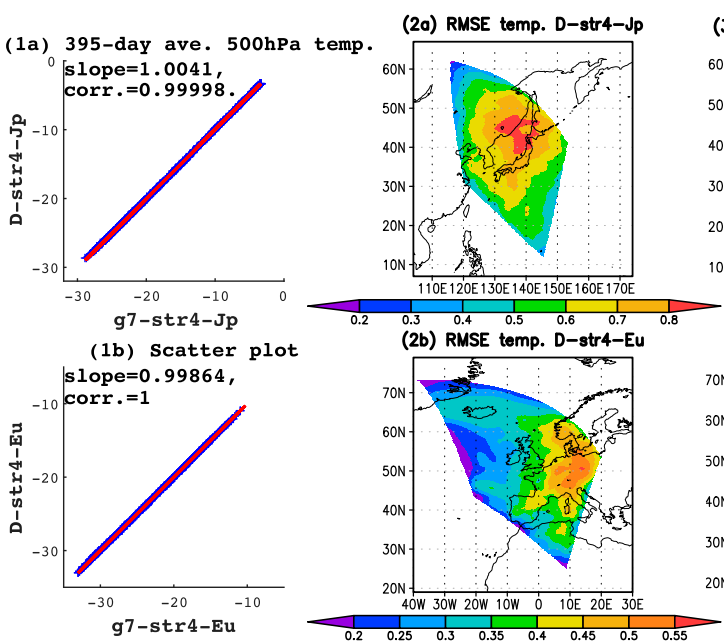

(1c) Scatter plot

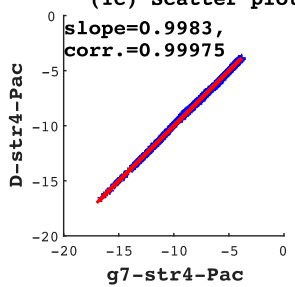

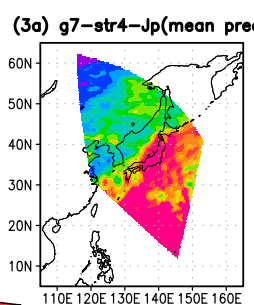

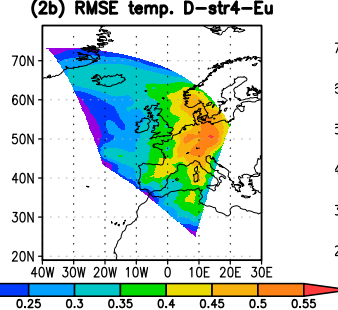

(2c) RMSE temp. D-str4-Poc

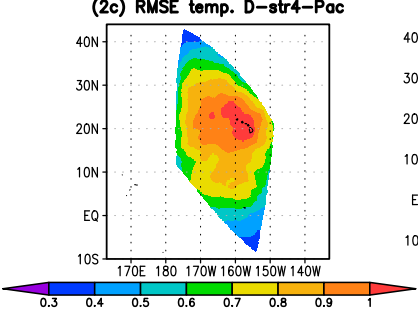

(3c) g7-str4-Eu

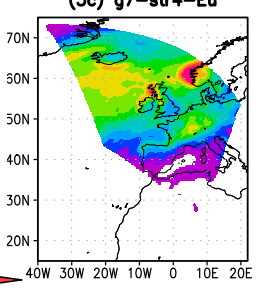

(3e) g7-str4-Poc

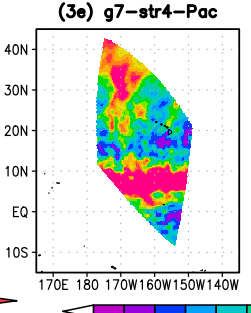

(3b) D-str4-Jp

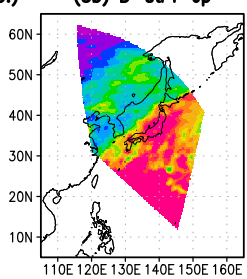

(3d) D-str4-Eu
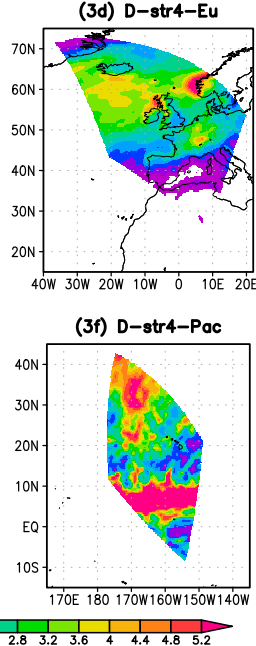

(4a) 395-day ave. surf precip.
${ }^{15}[$ slope $=1.0202$,

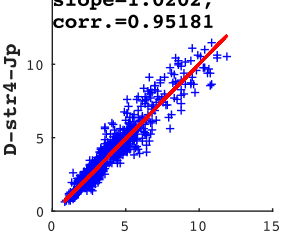

g7-str4-Jp

(4b) Scatter plot

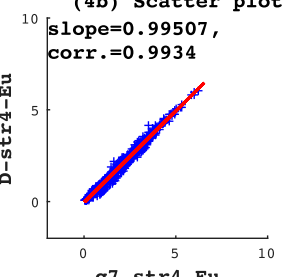

g7-str4-Eu

(4c) Scatter plot

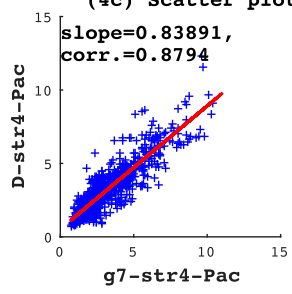

FIG. 11. The 395-day (from 0000 UTC 1 Mar 2011 to 0000 UTC 1 Apr 2012) mean temperature (in K) at $500 \mathrm{hPa}$ and surface precipitation (in mm day ${ }^{-1}$ ) statistics between the global NICAM and the regional D-NICAM. (from top to bottom) The regional domains centered over Japan, western Europe, and the Pacific near Hawaii are shown. (from left to right) (1a)-(1c) Scatterplots of the 395-day mean temperatures at $500 \mathrm{hPa}$ between the global and the regional simulations, (2a)-(2c) temporal RMSEs of temperature at $500 \mathrm{hPa}$, (3a)-(3f) mean surface precipitation, and (4a)-(4c) scatterplots of the mean surface precipitation.

observed to have the largest amount of precipitation during the winter period as a result of the westerly wind flows [Figs. 14(2c),(2d)], but the deviations [red lines in Figs. $14(2 \mathrm{~g}),(2 \mathrm{~h})]$ and seasonal correlations [Fig. 12 (4b)] show that the largest discrepancies did not occur in winter. This finding provides additional evidence that the large-scale extratropical cyclones in winter were relatively well reproduced, while the small-scale summer convective precipitation over the continents was not. The convective precipitation was highly sensitive to small environmental perturbation, even without explicit parameterizations. Larger errors in 500-hPa RMSE temperature and precipitation during the summer for simulations over Europe have also been reported in previous papers (Jones et al. 1995; Noguer et al. 1998; Beniston et al. 2007; Déqué et al. 2007). These previous authors argued that although lateral boundary forcing contributes to systematic error, internal regional physical processes strongly affect circulation patterns that induce large inconsistencies in the continental European summer, while during the winter, lateral boundary forcing is the major factor controlling the general circulation error. Our case further illustrates that the sensitive nature of convection contributes to systematic errors during the summer.

For D-str4-Pac, larger RMSEs were seen throughout the year, with no clear seasonal variations [Figs. 14(2g), (2h)]. As previously discussed, differences in the schemes and size dependencies of the convective precipitation parameterizations between global models and regional LAMs can lead to large discrepancies in wintertime precipitation patterns in the tropics, where precipitation is controlled by deep convection, but much less so at the midlatitudes, where the large-scale synoptic process is a controlling factor (Herceg et al. 2006). Our finding is the same, but again, the cause may be the highly stochastic (chaotic) nature of the convective system itself rather than differences in a parameterization scheme because slightly different fields can produce completely different outlooks.

Figure 15 shows the kinetic energy spectra at $200 \mathrm{hPa}$, similar to the results shown in Fig. 10, and again, all the simulations showed nearly equal amounts of energy in the larger wave (low frequency) domain for global NICAM and D-NICAM, while all the regional D-NICAM results had slightly lower energies in the small wave (high frequency) domain, possibly because of the lower 


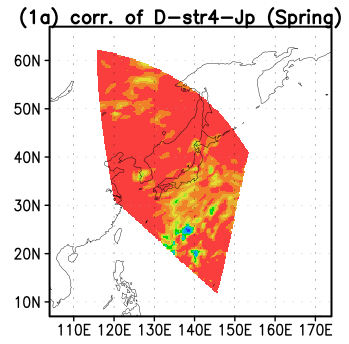

(1b) corr. of D-str4-Eu (Spring)

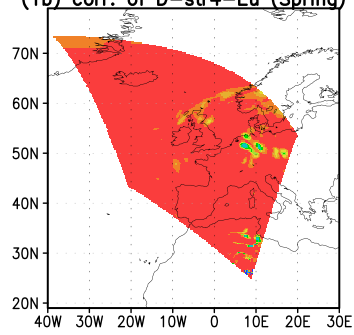

(1c) corr. of D-str4-Pac (Spring)

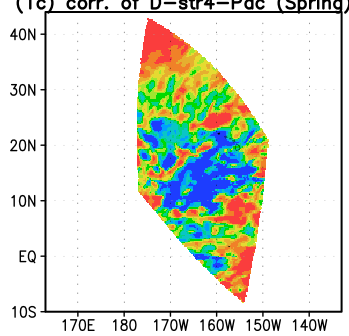

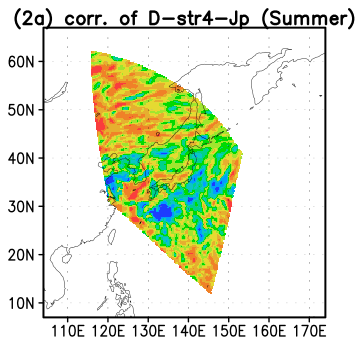
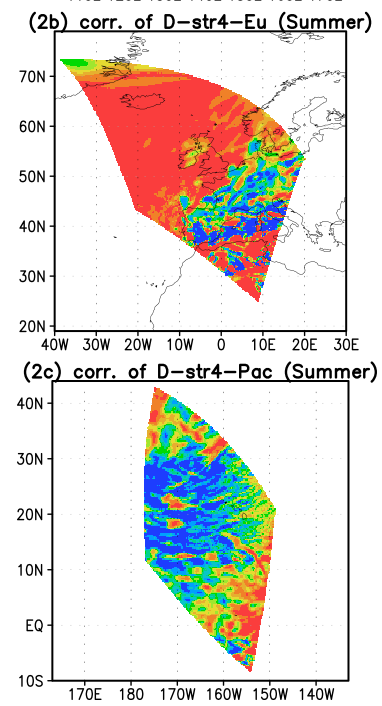
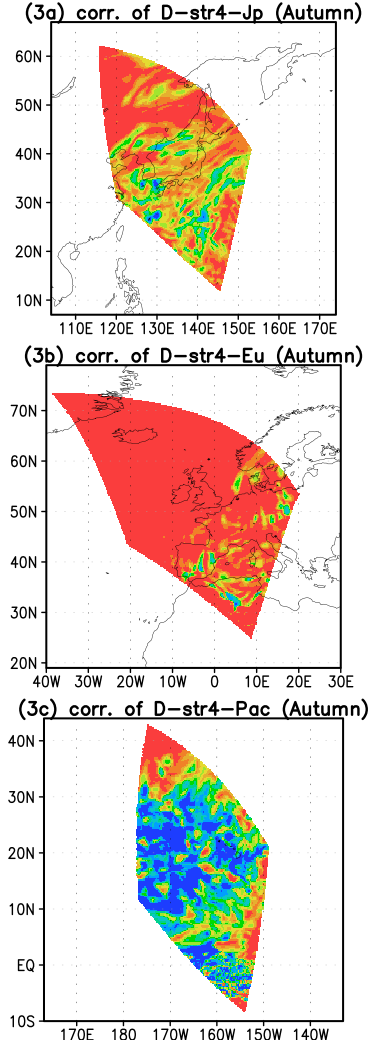
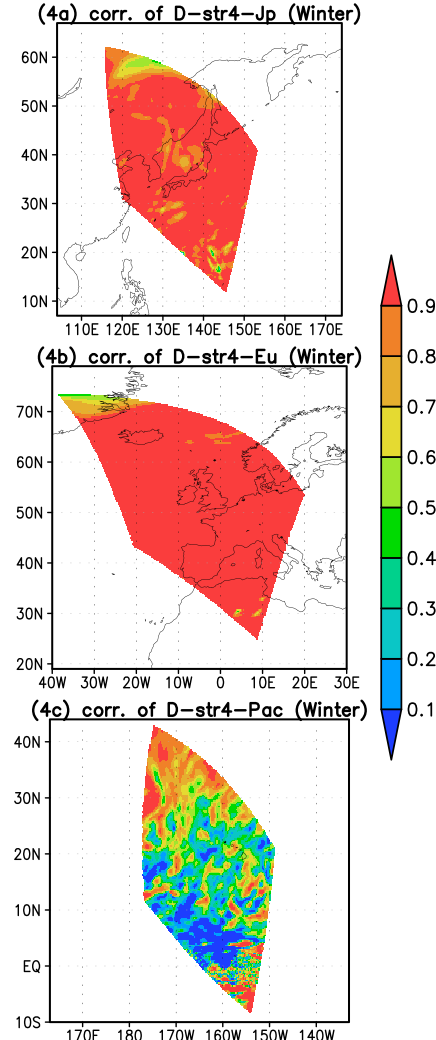

FIG. 12. As in Fig. 9, but for different regional domains. (from top to bottom) Domains are centered over Japan, western Europe, and the Pacific near Hawaii.

temporal resolution of the driving LB dataset and the lack of sufficient downscaling. In addition, the energy spectra of all of the different simulations were more closely aggregated in the high-frequency region, implying a strong resolution dependency on the smallscale flows, in contrast to Fig. 10, in which all the simulations were aggregated in the low-frequency domain, implying the location dependency of the largescale flows.

In our simulations, all of the midlatitude simulations over North America, Japan, and Europe had the same trends of large deficiencies during the summer. Figure 16 depicts the time series spatial correlations of the largeand small-scale temperatures and precipitation distributions for the global models and regional LAMs. A Gaussian filter with a sigma of approximately $300 \mathrm{~km}$ was applied to separate the large- and small-scale fields on the 3-hourly results; spatial correlations were then calculated separately for each scale, and 2-day running means were applied to the resulting time series. The large-scale (blue line) temperature correlations (Figs. 16a,e,i,m) were consistently high for the entire duration, except for a few spikes in the summer, in all of the simulations, while the small-scale (red line) temperature dropped during the summer for D-str4 (Fig. 16a), D-str4-Jp (Fig. 16e), and D-str4-Eu (Fig. 16i) and in all seasons for D-str4-Pac (Fig. 16m). We can assume that smaller-scale convection and tropical cyclones in the summer may affect the 500-hPa temperature fields at small scales (red line) but not for large scales (blue line). Similarly, for the 200-hPa horizontal velocities $u$ and $v$, the influences of the smaller-scale convective flows in the summer on the large-scale (mean) flows (blue line) were somewhat limited. Precipitation rate was an exception because both smalland large-scale correlations dropped in the same way to low values (Figs. 16b,f,j,n). It is likely that the small-scale summer precipitation was sufficiently strong to affect the large-scale (mean) distribution of the precipitation.

\section{Summary and conclusions}

Our experiments were conducted to understand the extent of LBC errors and how they propagate in time and affect the systematic errors. We examined the systematic errors of the LAMs from three different viewpoints-mean bias, stochastic error at each 

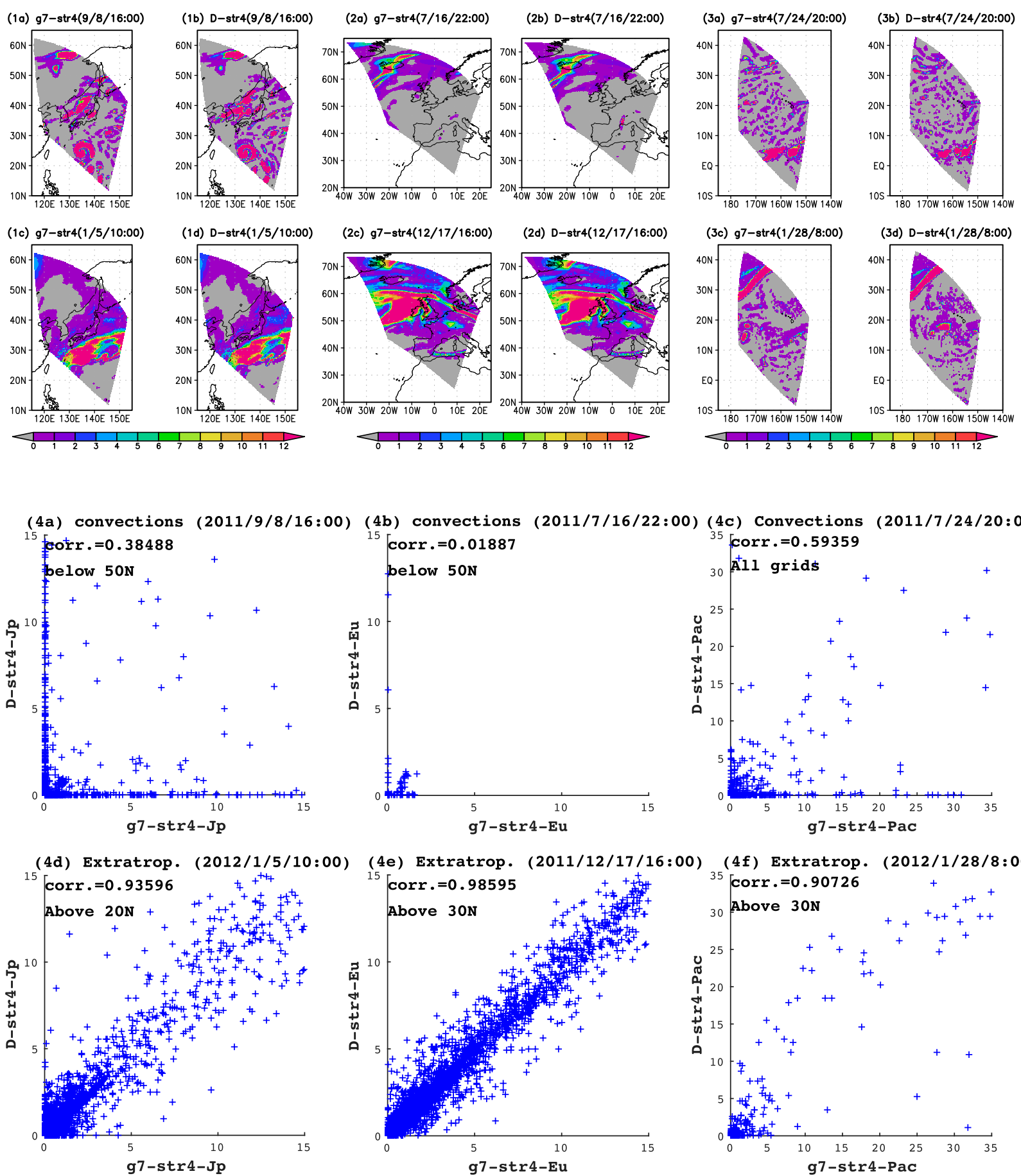

FIG. 13. As in Fig. 8, but for different regional domains. The instantaneous precipitation rates (in mm day ${ }^{-1}$ ) for the domains centered over (1a)-(1d) Japan, (2a)-(2d) western Europe, and (3a)-(3d) the Pacific near Hawaii. The scatterplots for the instantaneous distributions of the $(4 a)-(4 c)$ summer convection and $(4 d)-(4 f)$ extratropical cyclones are shown.

instance of time, and LBC error-and systematically analyzed how initial LBC errors can induce stochastic errors and mean biases. We prepared nonhydrostatic global and regional LAM climate models that shared dynamics, physics, and grid points to minimize model bias and ignored some possible causes of LBC error, and we were therefore able to assume that the global simulations were perfect comparative references for the regional simulations. We first ran two 18-day simulations using the regional LAMs: one to further minimize the 

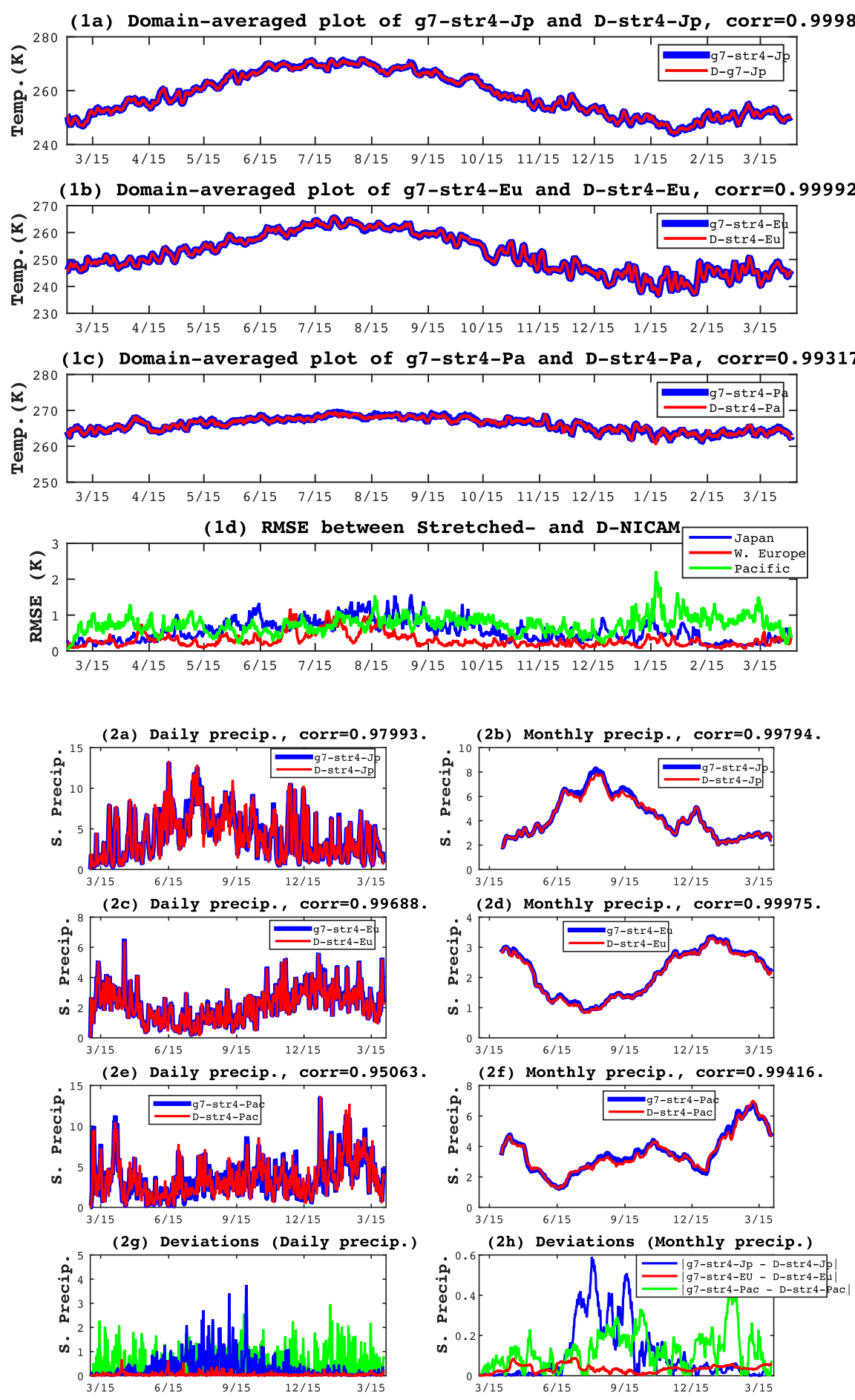

FIG. 14. As in Fig. 7, but for the time series plots of domain-averaged temperature and spatial RMSE at $500 \mathrm{hPa}$ and for different regional domains centered over (1a) Japan (g7-str4-Jp and D-str4-Jp), (1b) western Europe (g7-str4-Eu and D-str4-Eu), and (1c) the Pacific (g7-str4-Pac and D-str4-Pac). (1d) RMSEs are shown using a blue line for D-str4-Jp, a red line for D-str4-Eu, and a green line for D-str4-Pac. In addition, time series plots of domain-averaged daily and monthly precipitation (in mm day ${ }^{-1}$ ) centered over (2a), (2b) Japan; (2c), (2d) western Europe; and (2e),(2f) the Pacific are displayed: (left) daily and (right) monthly precipitation rates. In addition, the magnitudes of the deviations between the LAM regional and the global simulations of (2g) daily and (2h) monthly precipitation for D7-str16, D7-str4, and D-g7 are shown as blue, red, and green lines, respectively. 
TABLE 5. As in Table 3, but for the g7-str4-Jp, g7-str4-Eu, and g7-str4-Pac regional LAMs.

\begin{tabular}{ccccc}
\hline \hline Precipitation correlation & Hourly & Daily & Weekly & Monthly \\
\hline g7-str4-Jp & 0.9573 & 0.9799 & 0.9916 & 0.9979 \\
g7-str4-Eu & 0.9929 & 0.9969 & 0.9987 & 0.9997 \\
g7-str4-Pac & 0.8953 & 0.9506 & 0.9844 & 0.9942 \\
\hline
\end{tabular}

LBC errors by updating the LB data at each time step (15s) and another to apply the LB data with 3-hourly update frequency. A direct comparison revealed that although the magnitudes of the error may have differed, the processes by which the LBC errors initiated and grew were similar. Therefore, by applying the 3-hourly updated LB data, we compared the 395-day simulations using the global and regional LAMs centered on the continental United States under the three different domain sizes. The resulting temporal mean statistics of the temperatures and precipitation displayed some domain size and seasonal dependencies on the bias. The temperature biases tended to appear downwind of large-scale flows away from boundaries and were larger for larger domain sizes (Fig. 4). A strong surface precipitation bias signal was seen in summer, when small-scale convective precipitation and tropical cyclones were frequent (Fig. 6). However, orographic precipitation in the Pacific Northwest in winter was generally well reproduced. The time series of the spatial RMSEs of the temperature and precipitation revealed seasonal variations in the instantaneous error (a stochastic error); the error intensified in summer, except in D-g7, and large RMSE values were observed through the winter as a result of the deviations in large-scale flows within its larger domain size. In addition, 3-month temporal correlations of surface precipitation in each season showed that the locations of low correlation coincided with those of small-scale convective precipitation.

Additional simulations using different regions over Japan, western Europe, and the Pacific near Hawaii were also conducted. From the 3-month temporal correlations of daily surface precipitation (Fig. 12), D7str4-Pac in the tropics had low correlations throughout the year because of convective precipitation. By contrast, D7-str4-Eu displayed low correlations over the continents during summer, but in winter, precipitation was generally well correlated when the largescale extratropical cyclones were frequent, and the precipitation rates were maximized. It is our understanding that the LBC error can perturb the domain and strongly influence small-scale structures in the forms of convective precipitation and tropical cyclones, but large-scale extratropical cyclones are generally intact if the domain sizes are somewhat manageable. The time series of the spatial correlations for large- and

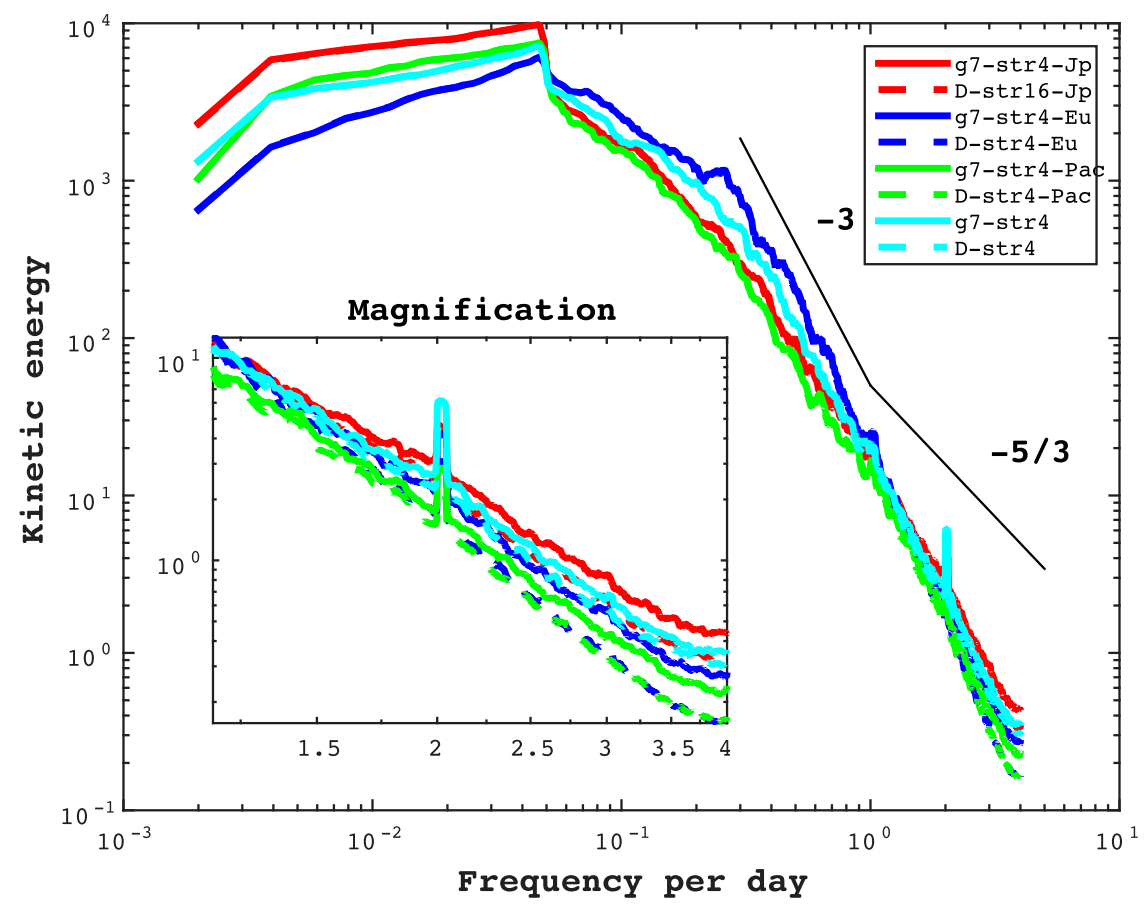

FIG. 15. As in Fig. 10, but the lines are for g7-str4-Jp (red), D-str4-Jp (dashed red), g7-str4-Eu (blue), D-str4-Eu (dashed blue), g7-str4-Pac (green), D-str4-Pac (dashed green), g7-str4 (cyan), and D-str4 (dashed cyan). 

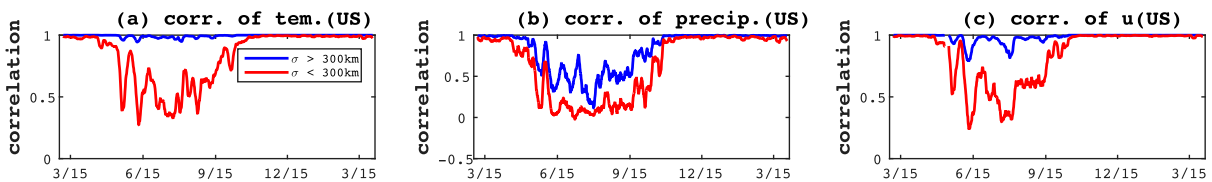

(e) corr. of tem. (Jp)
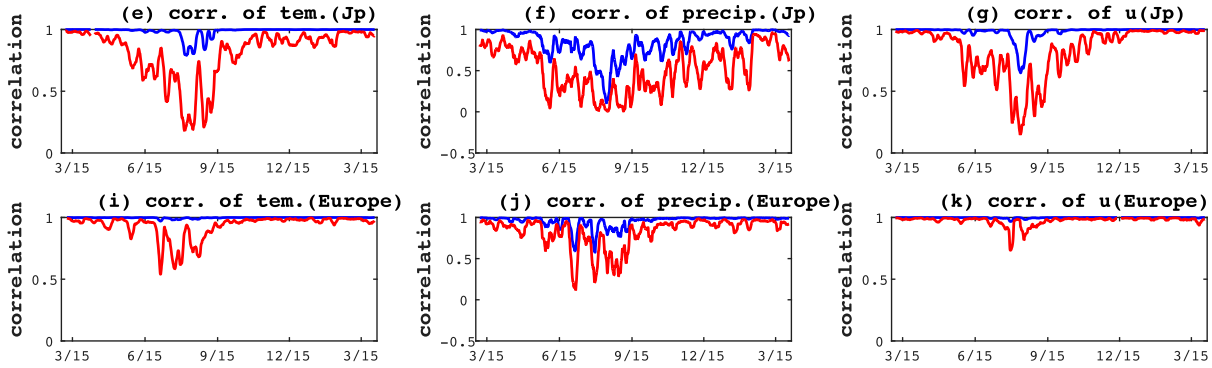

(o) corr. of u(Pac.)
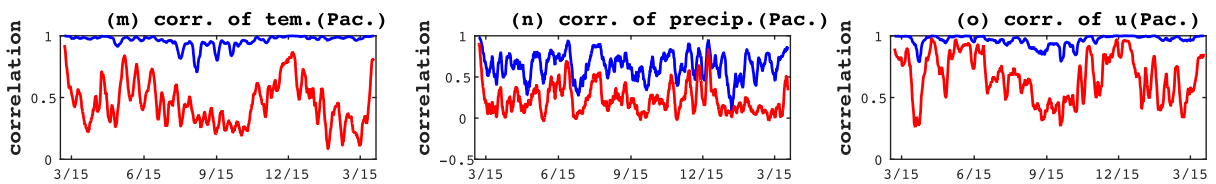
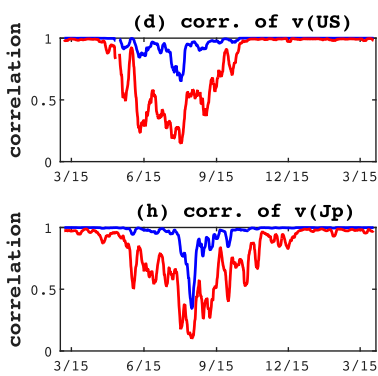

(1) corr. of $v$ (Europe)

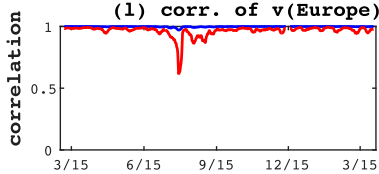

(p) corr. of $\mathrm{v}$ (Pac.)

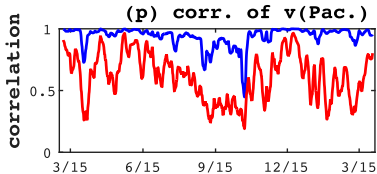

FIG. 16. Time series of spatial correlations for large-scale (blue lines) and small-scale (red lines) flows between the global and regional models. (from left to right) The correlations of temperature at $500 \mathrm{hPa}$, surface precipitation, and horizontal velocities $u$ and $v$ at $200 \mathrm{hPa}$. (from top to bottom) The correlations for the regional domains centered over North America (g7-str4 and D-str4), Japan (g7-str4-Jp and D-str4-Jp), western Europe (g7-str4-Eu and D-str4-Eu), and the Pacific near Hawaii (g7-str4-Pac and D-str4-Pac). The large- and small-scale flows were obtained by applying a Gaussian filter with a sigma value of $300 \mathrm{~km}$ to separate the flows into two different scales, and spatial correlations were calculated at each scale separately.

small-scale flows between the global and regional LAMs revealed that small-scale convective flows did not influence the large-scale (mean) temperature and horizontal velocity distributions, except for the distribution of large-scale precipitation. It is hypothesized that if the domain size were sufficiently small such that large-scale flows do not deviate, then LBC errors would not cause errors when generating the mean statistics of velocities and temperatures; however, the expected "added values" of small flows that are not topographically induced are greatly affected. This is not an issue with respect to the parameterization schemes but rather the uncertainty in a convective system itself, and applications of either long-term means, internal nudging, or ensemble experiments may be recommended in some situations.

Acknowledgments. Parts of this research were supported by funds from ERCA/Environment Research and Technology Development Fund (ERTDF)/S-12, the K-computer HPCI System Research project (hp160004, hp170017), and JST CREST Grant JPMJCR15K4, Japan.

\section{REFERENCES}

Antic, S., R. Laprise, B. Denis, and R. de Elía, 2006: Testing the downscaling ability of a one-way nested regional climate model in regions of complex topography. Climate Dyn., 26, 305-325, https://doi.org/10.1007/s00382-005-0046-z.
Ban, N., J. Schmidli, and C. Schär, 2014: Evaluation of the convection-resolving regional climate modeling approach in decade-long simulations. J. Geophys. Res. Atmos., 119, 7889-7907, doi:10.1002/2014JD021478.

,$- \ldots$, and -2015 : Heavy precipitation in a changing climate: Does short-term summer precipitation increase faster? Geophys. Res. Lett., 42, 1165-1172, https://doi.org/10.1002/ 2014 GL062588.

Beniston, M., and Coauthors, 2007: Current and future extreme climatic events in Europe: Observations and modeling studies conducted within the EU PRUDENCE project. Climatic Change, 81, 71-95, https://doi.org/10.1007/s10584-006-9226-z.

Caian, M., and J.-F. Geleyn, 1997: Some limits to the variable-mesh solution and comparison with the nested-LAM solution. Quart. J. Roy. Meteor. Soc., 123, 743-766, https://doi.org/ 10.1002/qj.49712353911.

Chapman, E. G., W. I. Gustafson Jr., J. C. Barnard, S. J. Ghan, M. S. Pekour, and J. D. Fast, 2009: Coupling aerosol-cloudradiative processes in the WRF-Chem model: Investigating the radiative impact of large point sources. Atmos. Chem. Phys., 9, 945-964, https://doi.org/10.5194/acp-9-945-2009.

Denis, B., R. Laprise, D. Caya, and J. Côté, 2002: Downscaling ability of one-way nested regional climate models: The Big Brother Experiment. Climate Dyn., 18, 627-646, https://doi.org/ 10.1007/s00382-001-0201-0.

$\ldots, \ldots$, and -2003 : Sensitivity of a regional climate model to the spatial resolution and temporal updating frequency of lateral boundary conditions. Climate Dyn., 20, 107-126, https://doi.org/10.1007/s00382-002-0264-6.

Déqué, M., and J. Ph. Piedelievre, 1995: High-resolution climate simulation over Europe. Climate Dyn., 11, 321-339, https:// doi.org/10.1007/BF00215735.

_ , and Coauthors, 2007: An intercomparison of regional climate simulations for Europe: Assessing uncertainties in 
model projections. Climatic Change, 81 (Suppl. 1), 53-70, https://doi.org/10.1007/s10584-006-9228-x.

Dimitrijevic, M., and R. Laprise, 2005: Validation of the nesting technique in a regional climate model and sensitivity tests to the resolution of the lateral boundary conditions during summer. Climate Dyn., 25, 555-580, https://doi.org/10.1007/ s00382-005-0023-6.

Feser, F., B. Rockel, H. Von Storch, J. Winterfeldt, and M. Zahn, 2011: Regional climate models add value to global model data: A review and selected examples. Bull. Amer. Meteor. Soc., 92, 1181-1192, https://doi.org/10.1175/ 2011BAMS3061.1.

Flato, G., and Coauthors, 2013: Evaluation of climate models. Climate Change 2013: The Physical Science Basis, T. F. Stocker et al., Eds., Cambridge University Press, 741-866.

Flesch, T. K., and G. W. Reuter, 2012: WRF Model simulation of two Alberta flooding events and the impact of topography. J. Hydrometeor., 13, 695-708, https://doi.org/10.1175/ JHM-D-11-035.1.

Foley, A. M., 2010: Uncertainty in regional climate modelling: A review. Prog. Phys. Geogr., 34, 647-670, https://doi.org/ 10.1177/0309133310375654.

Fosser, G., S. Khodayar, and P. Berg, 2015: Benefit of convection permitting climate model simulations in the representation of convective precipitation. Climate Dyn., 44, 45, https://doi.org/ 10.1007/s00382-014-2242-1.

Fox-Rabinovitz, M. S., J. Cote, M. Deque, B. Dugas, and J. McGregor, 2006: Variable resolution general circulation models: Stretched-Grid Model Intercomparison Project (SGMIP). J. Geophys. Res., 111, D16104, https://doi.org/ 10.1029/2005JD006520.

Giorgi, F., and L. O. Mearns, 1991: Approaches to the simulation of regional climate change: A review. Rev. Geophys., 29, 191-216, https://doi.org/10.1029/90RG02636.

$\longrightarrow$, and — 1999: Introduction to special section: Regional Climate Modeling revisited. J. Geophys. Res., 104, 6335-6352, https://doi.org/10.1029/98JD02072.

__ , and Coauthors, 2001: Regional climate informationEvaluation and projections. Climate Change 2001: The Scientific Basis, J. T. Houghton et al., Eds., Cambridge University Press, 583-638, http://works.bepress.com/ william-gutowski/56/.

Goto, D., and Coauthors, 2015: Application of a global nonhydrostatic model with a stretched-grid system to regional aerosol simulations around Japan. Geosci. Model Dev., 8 , 235-259, https://doi.org/10.5194/gmd-8-235-2015.

Hashimoto, A., J. M. Done, L. D. Fowler, and C. L. Bruyère, 2016: Tropical cyclone activity in nested regional and global gridrefined simulations. Climate Dyn., 47, 497-508, https://doi.org/ 10.1007/s00382-015-2852-2.

Herceg, D., A. H. Sobel, L. Sun, and S. E. Zebiak, 2006: The Big Brother Experiment and seasonal predictability in the NCEP Regional Spectral Model. Climate Dyn., 27, 69-82, https://doi.org/10.1007/s00382-006-0130-z.

Hong, S.-Y., and J.-W. Lee, 2009: Assessment of the WRF model in reproducing a flash-flood heavy rainfall event over Korea. Atmos. Res., 93, 818-831, https://doi.org/ 10.1016/j.atmosres.2009.03.015.

Jones, R. G., J. M. Murphy, and M. Noguer, 1995: Simulation of climate change over Europe using a nested regional-climate model. I: Assessment of control climate, including sensitivity to location of lateral boundaries. Quart. J. Roy. Meteor. Soc., 121, 1414-1449, doi:10.1002/qj.49712152610.
Juang, H.-M. H., and S.-Y. Hong, 2001: Sensitivity of the NCEP Regional Spectral Model to domain size and nesting strategy. Mon. Wea. Rev., 129, 2904-2922, https://doi.org/10.1175/ 1520-0493(2001)129<2904:SOTNRS > 2.0.CO;2.

Køltzow, M., T. Iversen, and J. E. Haugen, 2008: Extended big-brother experiments: The role of lateral boundary data quality and size of integration domain in regional climate modelling. Tellus, $\mathbf{6 0 A}$, 398-410, https://doi.org/10.1111/j.1600-0870.2008.00309.x.

Laprise, R., and Coauthors, 2008: Challenging some tenets of regional climate modelling. Meteor. Atmos. Phys., 100, 3-22, https://doi.org/10.1007/s00703-008-0292-9.

Larsen, M. A. D., P. Thejll, J. H. Christensen, J. C. Refsgaard, and K. H. Jensen, 2013: On the role of domain size and resolution in the simulations with the HIRHAM region climate model. Climate Dyn., 40, 2903-2918, https://doi.org/10.1007/s00382-012-1513-y.

Leung, L. R., and S. J. Ghan, 1998: Parameterizing subgrid orographic precipitation and surface cover in climate models. Mon. Wea. Rev., 126, 3271-3291, https://doi.org/10.1175/ 1520-0493(1998)126<3271:PSOPAS > 2.0.CO;2.

— L. O. Mearns, F. Giorgi, and R. L. Wilby, 2003: Regional climate research: Needs and opportunity. Bull. Amer. Meteor. Soc., 84, 89-95, https://doi.org/10.1175/BAMS-84-1-89.

Lo, J. C., Z.-L. Yang, and R. A. Pielke Sr., 2008: Assessment of three dimensional dynamical climate downscaling methods using the Weather Research and Forecasting (WRF) model. J. Geophys. Res., 113, D09112, https://doi.org/10.1029/ 2007JD009216.

Matte, D., R. Laprise, and J. Thériault, 2016: Comparison between high-resolution climate simulations using single- and doublenesting approaches within the Big-Brother experimental protocol. Climate Dyn., 47, 3613-3626, https://doi.org/10.1007/ s00382-016-3031-9.

McGregor, J. L., 1997: Regional climate modelling. Meteor. Atmos. Phys., 63, 105-117, https://doi.org/10.1007/BF01025367.

Mearns, L. O., F. Giorgi, P. Whetton, D. Pabon, M. Hulme, and M. Lal, 2003: Guidelines for use of climate scenarios developed from regional climate model experiments. Data Distribution Centre, Intergovernmental Panel on Climate Change, 38 pp., http://www.ipcc-data.org/guidelines/ dgm_no1_v1_10-2003.pdf.

Mesinger, F., K. Veljovic, M. J. Fennessy, and E. L. Altshuler, 2012: Value added in regional climate modeling: Should one aim to improve on the large scales as well? Climate Change, A. Berger, F. Mesinger, and D. Sijacki, Eds., Springer, 201-214, https://doi.org/10.1007/978-3-7091-0973-1_15.

Nakanishi, M., and H. Niino, 2004: An improved MellorYamada level-3 model with condensation physics: Its design and verification. Bound-Layer Meteor., 112, 1-31, doi:10.1023/B:BOUN.0000020164.04146.98.

- and - 2009: Development of an improved turbulence closure model for the atmospheric boundary layer. J. Meteor. Soc. Japan, 87, 895-912, https://doi.org/10.2151/jmsj.87.895.

Noda, A. T., K. Oouchi, M. Satoh, H. Tomita, S. Iga, and Y. Tsushima, 2010: Importance of the subgrid-scale turbulent moist process: Cloud distribution in global cloud-resolving simulations. Atmos. Res., 96, 208-217, https://doi.org/10.1016/ j.atmosres.2009.05.007.

Noguer, M., R. Jones, and J. Murphy, 1998: Sources of systematic errors in the climatology of a regional climate model over Europe. Climate Dyn., 14, 691-712, https://doi.org/10.1007/ s003820050249.

Prein, A. F., A. Gobiet, M. Suklitsch, H. Truhetz, N. K. Awan, K. Keuler, and G. Georgievski, 2013a: Added value of con- 
vection permitting seasonal simulations. Climate Dyn., 41, 2655-2677, https://doi.org/10.1007/s00382-013-1744-6.

, G. J. Holland, R. M. Rasmussen, J. Done, K. Ikeda, M. P. Clark, and C. H. Liu, 2013b: Importance of regional climate model grid spacing for the simulation of heavy precipitation in the Colorado headwaters. J. Climate, 26, 4848-4857, https:// doi.org/10.1175/JCLI-D-12-00727.1.

— permitting climate modeling: Demonstrations, prospects, and challenges. Rev. Geophys., 53, 323-361, https://doi.org/ 10.1002/2014RG000475.

Putman, W. M., and M. Suarez, 2011: Cloud-system resolving simulations with the NASA Goddard Earth Observing System global atmospheric model (GEOS-5). Geophys. Res. Lett., 38, L16809, https://doi.org/10.1029/2011GL048438.

Ratnam, J. V., Y. Morioka, S. K. Behera, and T. Yamagata, 2015: A model study of regional air-sea interaction in the austral summer precipitation over southern Africa. J. Geophys. Res. Atmos., 120, 2342-2357, doi:10.1002/2014JD022154.

_- S. K. Behera, T. Doi, S. B. Ratna, and W. A. Landman, 2016: Improvements to the WRF seasonal hindcasts over South Africa by bias correcting the driving SINTEX-F2v CGCM fields. J. Climate, 29, 2815-2829, https://doi.org/10.1175/ JCLI-D-15-0435.1.

Rauscher, S. A., T. D. Ringler, W. C. Skamarock, and A. A. Mirin, 2013: Exploring a global multiresolution modeling approach using aquaplanet simulations. J. Climate, 26, 2432-2452, doi: http:// dx.doi.org/10.1175/JCLI-D-12-00154.1.

Rummukainen, M., 2010: State-of-the-art with regional climate models. Wiley Interdiscip. Rev.: Climate Change, 1, 82-96, https://doi.org/10.1002/wcc.8.

Sakaguchi, K., and Coauthors, 2015: Exploring a multiresolution approach using AMIP simulations. J. Climate, 28, 5549-5574, https://doi.org/10.1175/JCLI-D-14-00729.1.

Sasaki, H., K. Kurihara, I. Takayabu, and T. Uchiyama, 2008: Preliminary experiments of reproducing the present climate using the non-hydrostatic regional climate model. Sci. Online Lett. Atmos., 4, 25-28.

Satoh, M., T. Matsuno, H. Tomita, H. Miura, T. Nasuno, and S. Iga, 2008: Nonhydrostatic Icosahedral Atmospheric Model (NICAM) for global cloud resolving simulations. J. Comput. Phys., 227, 3486-3514, https://doi.org/10.1016/j.jcp.2007.02.006.

, and Coauthors, 2014: The Non-hydrostatic Icosahedral Atmospheric Model: Description and development. Prog. Earth Planet. Sci., 1, 18, https://doi.org/10.1186/s40645-014-0018-1.
Sekiguchi, M., and T. Nakajima, 2008: A k-distribution-based radiation code and its computational optimization for an atmospheric general circulation model. J. Quant. Spectrosc. Radiat. Transfer, 109, 2779-2793, https://doi.org/10.1016/j.jqsrt.2008.07.013.

Skamarock, W. C., and Coauthors, 2008: A description of the Advanced Research WRF version 3. NCAR Tech. Note NCAR/TN-475+STR, 113 pp., http://dx.doi.org/10.5065/ D68S4MVH.

— J. B. Klemp, M. G. Duda, L. Fowler, S.-H. Park, and T. D. Ringler, 2012: A multiscale nonhydrostatic atmospheric model using centroidal Voronoi tesselations and C-grid staggering. Mon. Wea. Rev., 140, 3090-3105, https://doi.org/ 10.1175/MWR-D-11-00215.1.

Takata, K., S. Emori, and S. Watanabe, 2003: Development of the minimal advanced treatments of surface interaction and runoff. Global Planet. Change, 38, 209-222, https://doi.org/ 10.1016/S0921-8181(03)00030-4.

Tomita, H., 2008a: A stretched grid on a sphere by new grid transformation. J. Meteor. Soc. Japan, 86A, 107-119, https:// doi.org/10.2151/jmsj.86A.107.

_ 2008b: New microphysics with five and six categories with diagnostic generation of cloud ice. J. Meteor. Soc. Japan, 86A, 121-142, https://doi.org/10.2151/jmsj.86A.121.

—_, and M. Satoh, 2004: A new dynamical framework of nonhydrostatic global model using the icosahedral grid. Fluid Dyn. Res., 34, 357-400, https://doi.org/10.1016/ j.fluiddyn.2004.03.003.

Uchida, J., M. Mori, H. Nakamura, M. Satoh, K. Suzuki, and T. Nakajima, 2016: Error and energy budget analysis of a nonhydrostatic stretched-grid global atmospheric model. Mon. Wea. Rev., 144, 1423-1447, https://doi.org/10.1175/MWR-D-15-0271.1.

Wang, Y., L. R. Leung, J. L. McGregor, D.-K. Lee, W.-C. Wang, Y. Ding, and F. Kimura, 2004: Regional climate modeling: Progress, challenges, and prospects. J. Meteor. Soc. Japan, 82, 1599-1628, https://doi.org/10.2151/jmsj.82.1599.

Warner, T. T., R. A. Peterson, and R. E. Treadon, 1997: A tutorial on lateral boundary conditions as a basic and potentially serious limitation to regional numerical weather prediction. Bull. Amer. Meteor. Soc., 78, 2599-2617, https://doi.org/ 10.1175/1520-0477(1997)078<2599:ATOLBC>2.0.CO;2.

Zarzycki, C. M., M. N. Levy, C. Jablonowski, J. R. Overfelt, M. A. Taylor, and P. A. Ullrich, 2014: Aquaplanet experiments using CAM's variable-resolution dynamical core. J. Climate, 27, 5481-5503, https://doi.org/10.1175/ JCLI-D-14-00004.1. 